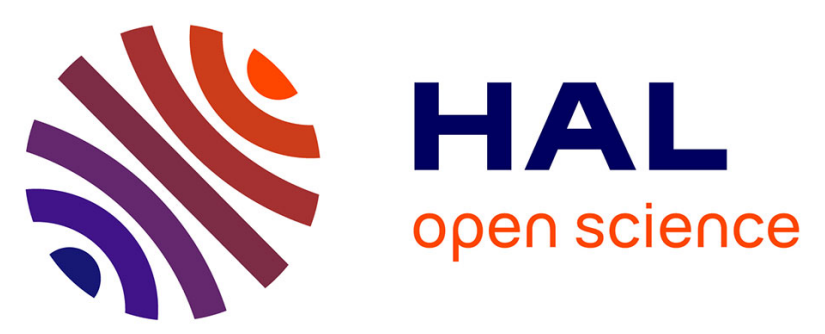

\title{
INTERNATIONAL TRAVELLING AND TRADE: FURTHER EVIDENCE FOR THE CASE OF SPANISH WINE BASED ON FRACTIONAL VAR SPECIFICATIONS
}

\author{
Luis Alberiko Gil-Alana, Christian Fischer
}

\section{To cite this version:}

Luis Alberiko Gil-Alana, Christian Fischer. INTERNATIONAL TRAVELLING AND TRADE: FURTHER EVIDENCE FOR THE CASE OF SPANISH WINE BASED ON FRACTIONAL VAR SPECIFICATIONS. Applied Economics, 2009, 42 (19), pp.2417-2434. 10.1080/00036840701858083 . hal00582245

\section{HAL Id: hal-00582245 \\ https://hal.science/hal-00582245}

Submitted on 1 Apr 2011

HAL is a multi-disciplinary open access archive for the deposit and dissemination of scientific research documents, whether they are published or not. The documents may come from teaching and research institutions in France or abroad, or from public or private research centers.
L'archive ouverte pluridisciplinaire HAL, est destinée au dépôt et à la diffusion de documents scientifiques de niveau recherche, publiés ou non, émanant des établissements d'enseignement et de recherche français ou étrangers, des laboratoires publics ou privés. 


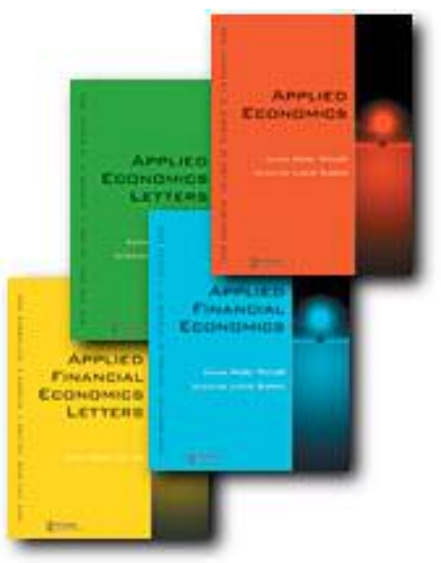

\section{INTERNATIONAL TRAVELLING AND TRADE: FURTHER EVIDENCE FOR THE CASE OF SPANISH WINE BASED ON FRACTIONAL VAR SPECIFICATIONS}

\begin{tabular}{|r|l|}
\hline Journal: & Applied Economics \\
\hline Manuscript ID: & APE-07-0355.R1 \\
\hline Journal Selection: & Applied Economics \\
\hline Aute Submitted by the & 06-Dec-2007 \\
\hline Complete List of Authors: & $\begin{array}{l}\text { Gil-Alana, Luis; Universidad de Navarra, Faculty of Economics } \\
\text { Fischer, Christian; University of Bonn, Agricultural Economics }\end{array}$ \\
\hline JEL Code: & $\begin{array}{l}\text { F14 - Country and Industry Studies of Trade < F1 - Trade < F - } \\
\text { International Economics, C22 - Time-Series Models < C2 - } \\
\text { Econometric Methods: Single Equation Models < C - Mathematical } \\
\text { and Quantitative Methods, L83 - } \\
\text { Sports|Gambling|Recreation|Tourism < L8 - Industry Studies: } \\
\text { Services < L - Industrial Organization, Q13 - Agricultural Markets } \\
\text { and Marketing|Cooperatives|Agribusiness < Q1 - Agriculture < Q - } \\
\text { Agricultural and Natural Resource Economics }\end{array}$ \\
\hline Keywords: & \begin{tabular}{l} 
International trade, Multivariate models, Fractional VAR, Tourism \\
\hline
\end{tabular} \\
\hline \multicolumn{2}{|l}{} \\
\hline
\end{tabular}

\section{\$) ScholarONE" \\ Manuscript Central}




\title{
INTERNATIONAL TRAVELLING AND TRADE: FURTHER EVIDENCE FOR THE CASE OF SPANISH WINE BASED ON FRACTIONAL VAR SPECIFICATIONS
}

\author{
Luis A. Gil-Alana* \\ University of Navarra, Pamplona, Spain \\ and \\ Christian Fischer** \\ University of Bonn, Bonn, Germany
}

\begin{abstract}
This paper deals with the relationship between international travelling and trade. For this purpose we focus on a particular case study: the connection between the Spanish wine exports to Germany and the German travellers to Spain. Unlike previous studies we use a methodology based on fractional vector autoregressive models, which permits us to compute the impulse responses in a similar way as in the standard VAR case. The results show that the orders of integration of the two series are constrained between 0 and 1, being higher for the arrivals series than for the exports. The impulse response analysis reveals that an increase in travelling produces a positive initial impact on trade though it tends to disappear in the long run.
\end{abstract}

JEL Classification: C22, F14, Q13, L83

Keywords: International trade; Multivariate models; Fractional VAR; Tourism.

Corresponding author: $\quad$ Luis A. Gil-Alana

University of Navarra

Faculty of Economics

Edificio Biblioteca, Entrada Este

E-31080 Pamplona, SPAIN

Phone: 0034948425 625; Fax: 0034948425 626; Email: $\underline{\text { alana@ unav.es }}$

\footnotetext{
* The author gratefully acknowledges financial support from the Ministerio de Ciencia y Tecnologia (SEJ2005-07657, Spain).

** The author gratefully acknowledges financial support from the H. Wilhelm Schaumann Stiftung, Hamburg, Germany.

The authors are grateful for helpful comments from Alison Burrell on the first draft of this paper. Comments of an anonymous referee are also gratefully acknowledged.
} 


\title{
INTERNATIONAL TRAVELLING AND TRADE: FURTHER EVIDENCE FOR THE CASE OF SPANISH WINE BASED ON FRACTIONAL VAR SPECIFICATIONS
}

\begin{abstract}
This paper deals with the relationship between international travelling and trade. For this purpose we focus on a particular case study: the connection between the Spanish wine exports to Germany and the German travellers to Spain. Unlike previous studies we use a methodology based on fractional vector autoregressive models, which permits us to compute the impulse responses in a similar way as in the standard VAR case. The results show that the orders of integration of the two series are constrained between 0 and 1, being higher for the arrivals series than for the exports. The impulse response analysis reveals that an increase in travelling produces a positive initial impact on trade though it tends to disappear in the long run.
\end{abstract}

JEL Classification: C22, F14, Q13, L83

Keywords: International trade; Multivariate models; Fractional VAR; Tourism. 


\section{Introduction}

International trade of good and services has been shown to be influenced by many factors of either push or pull character. While no mainstream microeconomic model has yet been developed to establish theoretically the link between trade and tourism (see however, Fischer, 2007, for a first approach), a host of empirical work has emerged which shows that there may in fact be a connection between the flow of goods and people. Many studies attempt to test the hypothesis that movements of people can contribute to generate exports, but they may also stimulate imports. Tourism is thought to be able to promote cross-border exports by initiating entrepreneurial activities as a result of learning about new business opportunities while travelling. At the same time, demand for new products to be consumed back home may be created as a consequence of learning about them during foreign travel.

In previous work, for instance, Easton (1998) analysed whether Canadian total exports are complementary or substitutive to tourist arrivals, using pooled data regressions. He finds "some evidence of substitution of Canadian exports for tourist excursions to Canada" (p. 542) by showing that when the relative price of exports goes up, the number of tourists visiting Canada increases. Kulendran and Wilson (2000) analysed the direction of causality between different travel and (aggregate) trade categories for Australia and its four main trading partners. Their results show that travel Granger causes international trade in some cases and vice versa in others. Shan and Wilson (2001) replicate this latter approach and also find two-way Granger causality using aggregate data for China. Aradhyula and Tronstad (2003) used a simultaneous bivariate qualitative choice model to show that cross-border business trips have a significant and positive effect on US agribusinesses' propensity to trade. Fischer (2004) explored the connection between aggregate imports and imports of individual products 
and bilateral tourist flows, using an error correction model. His results show that tradetourism elasticities are consistently higher for individual products. Fischer and GilAlana (2007) quantified for the first time the length of the effect of tourism on international trade, using the case of German imports of Spanish wine. Depending on the wine type, the effect was estimated to last between 3 and 11 months, and on average 5.5 months.

What emerges from all these studies is that the existence, the direction, the strength (magnitude), and the length of the effect which tourism may have on international trade seems to depend on the analysed countries and products, and on the estimation technique used. Even if a range of results is now available, further empirical evidence is still useful in order to obtain a more complete and robust understanding of the actual nature of the relationship between international tourism and trade.

The aim of this study is therefore to expand existing knowledge on the traveltrade relationship for food products by generating further empirical evidence, based on recently developed fractional vector autoregressive (VAR) regression models. The analysis is more empirical than theoretical in the sense that it is attempted to test econometrically the hypothesis of a potentially existing relationship between travelling and exports. The used approach is not grounded in microeconomic supply or demand theory since no output, income or price data are taken into account in the econometric specification of the model. However, VAR models are generally accepted as theory-free methods for estimating economic relationships, thus being a legitimate alternative to the identification restrictions in structural models (Sims, 1980).

We focus exclusively on the relationship between the exports of Spanish wines to Germany and the number of German tourists travelling to Spain on a monthly basis. We do this for several reasons. First, wine has become a truly globalised industry with 
about $40 \%$ of production (in value terms) being exported worldwide in 2001 (Anderson, 2004). Second, in industrialized nations, wine is a commonly available commodity offered in a large variety mostly differentiated by production origin. Given that objective wine quality is hard to assess for non-expert consumers, the origin of a wine is often used as a short-cut quality indicator in cases where the country of origin is associated with a preferred holiday destination (Felzenstein, Hibbert and Vong, 2004). Last, wine imports have been shown to display a significant connection with tourism activities among a range of previously investigated products (Fischer, 2004). Nevertheless, it must be stated that in other industries (e.g., automotives), the traveltrade link may be much weaker or even inexistent.

This analysis differs from earlier work (Fischer and Gil-Alana, 2007) in various aspects. First, we extend the period of investigation both backwards and forwards implying that the results are expected to be more reliable. Moreover, we use export instead of import data, and more importantly, we use a different econometric modelling approach, which is multivariate rather than univariate as in Fischer and Gil-Alana (2007). Our method allows us to compute impulse response functions across variables and extend previous methodologies (e.g., VAR) in the use of fractional orders of integration for the series under investigation. As far as we know, this is the first empirical application using fractional vector autoregressive models, and, given the plethora of work on univariate fractionally integrated models in macro series, a work on multivariate (fractional) systems seems clearly overdue.

The structure of this article is as follows. First, for the two series under consideration, we produce univariate results based on fractional integration models. This approach is more flexible than others usually employed in the literature since it allows us to consider the cases of stationarity $\mathrm{I}(0)$ and nonstationarity $\mathrm{I}(1)$ as particular 
cases of our approach. Then, an innovative bivariate fractionally integrated model is used, i.e., we estimate jointly the orders of integration of the two series, and then analyse the cross impulse response functions. In other words, the effect of a shock in one variable over the other across time is computed. Here, we implicitly assume that the direction is uni-directional in the sense that we believe that travelling has an influence on exports and not the reverse case. ${ }^{1}$ The main innovation is that we allow fractional values for the orders of integration while standard methods suppose that they are either 0 or 1 . In the fifth section, the obtained results are compared to similar ones from other studies, before some conclusions are drawn. The appendices contain the technical details of the paper. Appendix A presents the functional form of the test statistic for testing fractional integration in a multivariate context. Appendix $\mathrm{B}$ refers to the fractional VAR model, specified for the bivariate case, and the subsequent sub-sections in that appendix describe the restriction required to the identification of the system for the two cases of white noise and autocorrelated disturbances.

\section{Econometric methodology}

This section is based on econometric grounds and we describe the techniques employed in the empirical work in Section 4. A crucial point when modelling univariate (or multivariate) time series is to correctly determine the order(s) of integration. In other words, in order to make statistical inference, the series are required to be stationary $\mathrm{I}(0)$. If they are not, a standard approach is to take first differences based on the assumption that the series are then nonstationary I(1). However, these two approaches $(I(0)$ and I(1)) may be too restrictive in the sense that many series may present a behaviour that is far from these two cases. In particular, the series may present a degree of dependence

\footnotetext{
${ }^{1}$ Fischer and Gil-Alana (2007) showed that German travellers to Spain cause (in the Granger causality tests) exports of Spanish wines to Germany. We should expect a similar pattern for imports.
} 
across time that is higher than the one described by the $\mathrm{I}(0)$ models (e.g., the exponential degree associated to the AR specifications) but smaller than the one obtained through the I(1) case. In such cases fractional differencing may be a viable approach. Given their theoretical appeal, fractional integration methods are increasingly used among applied economists, see, for instance, Barkoulas, Baum and Caglayan (1999), Tolvi (2003), Gil-Alana and Mendi (2005), Gschwandtner and Hauser (2007) or Assaf (2007).

For the purpose of the present paper we define an $\mathrm{I}(0)$ process as a covariance stationary process with spectral density function that is positive and finite. In this context, we say that a given raw time series $\left\{x_{t}, t=0, \pm 1, ..\right\}$ is $I(d)$ if:

$$
\begin{gathered}
(1-L)^{d} x_{t}=u_{t}, \quad t=1,2, \ldots, \\
x_{t}=0, \quad t \leq 0,
\end{gathered}
$$

where $u_{t}$ is $I(0)$ and where $L$ means the lag operator $\left(\operatorname{Lx}_{t}=x_{t-1}\right) .{ }^{2}$ Note that the polynomial above can be expressed in terms of its Binomial expansion, such that for all real d,

$$
(1-L)^{d}=\sum_{j=0}^{\infty}\left(\begin{array}{l}
d \\
j
\end{array}\right)(-1)^{j} L^{j}=1-d L+\frac{d(d-1)}{2} L^{2}-\ldots
$$

The literature has usually stressed the cases of $d=0$ and 1 , however, $d$ can be any real number. If $\mathrm{d}=0$ in (1), $\mathrm{x}_{\mathrm{t}}=\mathrm{u}_{\mathrm{t}}$, and a 'weakly autocorrelated' (e.g., AR) $\mathrm{x}_{\mathrm{t}}$ is allowed for. However, if $\mathrm{d}>0, \mathrm{x}_{\mathrm{t}}$ is said to be a long memory process, also called 'strongly autocorrelated', so-named because of the strong association between observations widely separated in time, and, as d increases beyond 0.5 and through $1, \mathrm{x}_{\mathrm{t}}$ can be viewed as becoming "more nonstationary", in the sense, for example, that the

\footnotetext{
${ }^{2}$ The condition $\mathrm{x}_{\mathrm{t}}=0, \mathrm{t} \leq 0$ is required for the Type II definition of fractional integration. For an alternative definition (Type I) see Marinucci and Robinson (1999).
} 
variance of partial sums increases in magnitude. ${ }^{3}$ These processes were introduced by Granger (1980, 1981), Granger and Joyeux (1980) and Hosking (1981), (though earlier work by Adenstedt, 1974, and Taqqu, 1975 shows an awareness of its representation), and were theoretically justified in terms of aggregation of ARMA processes with randomly varying coefficients by Robinson (1978), Granger (1980). If d belongs to the interval $(0,0.5) \mathrm{x}_{\mathrm{t}}$ is covariance stationary, but both the autocorrelations and the response of a variable to a shock take much longer time to disappear than in a standard $(d=0)$ stationary case. If $d \in[0.5,1)$ the series is no longer covariance stationary but is still mean reverting, with the effect of the shocks dying away in the long run. Thus, the fractional differencing parameter d plays a crucial role for our understanding of the economy and the macro dynamics. The majority of the applications of fractional integration in economic time series are based on univariate models, and we find among others the papers of Diebold and Rudebusch (1989), Baillie and Bollerslev (1994) and Gil-Alana and Robinson (1997). ${ }^{4}$

In this section we present a novel approach that permits us to consider a structural fractional VAR model from its reduced form and then obtain the impulse response functions. We derive a simple method in a multivariate fractional integration framework, which lets the data determine simultaneously the response of one variable over the other(s). This method presents some advantages with respect to previous approaches. First, the fractional integration approach allows to discern the order of integration of a given variable without the econometrician to choose between zero or one. The order of integration may be zero, a fraction of one, one or it could be even above one. Second, this approach is agnostic with respect to the order of integration of

\footnotetext{
${ }^{3}$ Models with d ranging between -0.5 and 0 are short memory and have been addressed as anti-persistent by Mandelbrot (1977), because the spectral density function is dominated by high frequency components.

${ }^{4}$ See also Baillie (1996) for a complete review of I(d) processes. Other recent surveys are those of Doukhan et al. (2003), Robinson (2003) and Gil-Alana and Hualde (2008).
} 
the variables before including them in a vector autoregressive (VAR) framework. As a result, pre-tests of the orders of integration of the variables are not required. Third, there is no disagreement between the responses of the variables in levels or in first differences as the responses in first differences are exactly the same as those implied by the variables in levels by construction.

The starting point is the following structural model:

$$
\begin{aligned}
& A D y_{t}=u_{t}, \quad t=1,2, \ldots \\
& u_{t}=G u_{t-1}+v_{t}, t=1,2, \ldots,
\end{aligned}
$$

where $\mathrm{A}$ is a (nxn) matrix of parameters; $\mathrm{D}$ is an (nxn) diagonal matrix of form:

$$
\left(\begin{array}{ccc}
(1-L)^{d_{1}} & 0 & 0 \\
0 & -- & 0 \\
0 & 0 & (1-L)^{d_{n}}
\end{array}\right)
$$

where $d_{1}, d_{2}, \ldots, d_{n}$ can be real values; $y_{t}$ is a $(n x 1)$ vector of the observable variables; $u_{t}$ is a ( $\mathrm{nx} 1)$ vector, which is assumed to be $\mathrm{I}(0)^{5} ; \mathrm{G}$ is another ( $\mathrm{nxn}$ ) matrix of parameters, and $v_{t}$ is a $(n \times 1)$ structural error vector with zero mean and diagonal variancecovariance matrix V. Substituting (2) into (3), we obtain

$$
A D y_{t}=G A D y_{t-1}+v_{t}, \quad t=1,2, \ldots
$$

implying that

$$
D y_{t}=A^{-1} \text { GA } D y_{t-1}+A^{-1} v_{t}, \quad t=1,2, \ldots \text {. }
$$

Using now the lag-operator (i.e., $\mathrm{Ly}_{\mathrm{t}}=\mathrm{y}_{\mathrm{t}-1}$ ):

$$
\left\lfloor I-A^{-1} G A L\right\rfloor D y_{t}=A^{-1} v_{t}, \quad t=1,2, \ldots,
$$

we get

$$
y_{t}=D^{-1}\left[I-A^{-1} G A L\right]^{-1} A^{-1} v_{t}, \quad t=1,2, \ldots
$$


which is the structural $\mathrm{MA}(\infty)$ representation of $\mathrm{y}_{\mathrm{t}}$.

In a multivariate system the number of procedures for fractional integration is very limited. Gil-Alana $(2003 \mathrm{a}, \mathrm{b})$ proposed an extension of the univariate tests of Robinson (1994) in the frequency domain, while Nielsen (2005) developed time domain versions of Gil-Alana's tests. ${ }^{6}$ These methods allow us to estimate a reduced-form model of form:

$$
\begin{gathered}
D y_{t}=\varepsilon_{t}, \quad t=1,2, \ldots \\
\varepsilon_{t}=F \varepsilon_{t-1}+w_{t}, \quad t=1,2, \ldots,
\end{gathered}
$$

where $\varepsilon_{t}$ is a (nx1) vector of the d-differenced variables; $F$ is a (nxn) matrix of parameters, and $\mathrm{w}_{\mathrm{t}}$ is an $\mathrm{I}(0)$ vector with variance-covariance matrix W. Substituting now (7) into (8),

$$
D y_{t}=F D y_{t-1}+w_{t}, \quad t=1,2, \ldots,
$$

implying that

$$
[I-F L] D y_{t}=w_{t}, \quad t=1,2, \ldots
$$

and then

$$
y_{t}=D^{-1}[I-F L]^{-1} w_{t}, \quad t=1,2, \ldots,
$$

which is the reduced-form $\mathrm{MA}(\infty)$ representation of $\mathrm{y}_{\mathrm{t}}$.

Note that the structural model in (6) has $2 n^{2}+2 n$ parameters to estimate: $n$ corresponding to the fractional differencing parameters in $\mathrm{D} ; 2 \mathrm{n}^{2}$ of the two matrices $\mathrm{A}$ and $\mathrm{G}$; and the $\mathrm{n}$ variances in $\mathrm{V}$. On the other hand, the reduced-form $\operatorname{MA}(\infty)$ representation in (10) contains $n+n^{2}+n(n+1) / 2$ parameters: the $n$ d-parameters in $D ; n^{2}$ in $\mathrm{F}$, and $\mathrm{n}(\mathrm{n}+1) / 2$ parameters of the variance-covariance matrix $\mathrm{W}$. Therefore, in order to

\footnotetext{
${ }^{5}$ An $\mathrm{I}(0)$ vector process is defined as a covariance stationary process with spectral density matrix that is positive definite.

${ }^{6}$ In another paper, Nielsen (2004) develops a likelihood approach in a fractionally integrated multivariate setting.
} 
identify the system we need to impose $(n / 2)(n+1)$ restrictions in the structural model. $N$ restrictions can be obtained by imposing a 1-unit variance in the variance-covariance matrix of $v_{t}$ in (3), V. However, $\left(n^{2}-n\right) / 2$ restrictions will still be required. Here, there are two possibilities: one is to impose triangularity in the A matrix in (2) - this would imply that the contemporaneous and the future effects of some of the variables on the others will be zero, which may be a relatively strong assumption in some cases. The second approach uses the Blanchard and Quah (1989) decomposition, which implies that in the long run some variables have no effect on the others. ${ }^{7,8}$

\section{The data}

We look at the relationship between trade and tourism by focussing on the interdependencies between the exports of Spanish wines to Germany and the number of German travellers to Spain.

The raw data were obtained from two different Eurostat databases. First, exports of Spanish wine (without sparkling wine) and of sparkling wine to Germany are taken from COMEXT "EU trade since 1995 by CN6" database. The arrivals of Germans in Spanish collective accommodation establishments are obtained from the "TOUR_OCC _NINRMW = Nights spent by non-residents - world geographical breakdown monthly data" database.

\section{The empirical work}

The first thing we do in this section is to model individually the two series, which are the total number of arrivals of Germany in Spanish collective accommodation

\footnotetext{
${ }^{7}$ A full description of these methods in presented in Appendix B.

${ }^{8}$ Alternative identification strategies also involving restrictions on the long run behaviour of the series are given in King, Plosser, Stock and Watson (1991). Other possibilites include restrictions on the sign and/or
} 
establishments, and the total Spanish wine exports (including sparkling wine) to Germany, monthly, from 1995M1 to 2006M7.

\section{INSERT FIGURE 1 ABOUT HERE}

A visual inspection at the series (in Figure 1) clearly shows that the two series present a seasonal component, which is changing over time. Dealing with seasonality is a matter that is still controversial. Deterministic approaches based on seasonal dummy variables are discouraged in this case in view of the changing seasonal patterns. A standard approach here is to perform a test of seasonal unit roots against the alternative of stochastic stationary behaviour. The most commonly-used method when dealing with monthly data is the one proposed by Beaulieu and Miron (1993), which is basically an extension of the Hylleberg, Engle, Granger and Yoo (HEGY, 1990) method to the monthly case. A drawback of this approach is that it is restricted to the case of I(1) and $\mathrm{I}(0)$ specifications and thus, it does not take into account fractional alternatives. Therefore, we also perform an alternative method (Robinson, 1994) that is nested in the fractional seasonal model of the form:

$$
\left(1-L^{12}\right)^{d} y_{t}=u_{t}, \quad t=1,2, \ldots,
$$

where the (seasonal) unit root corresponds to the case of $d=1 .{ }^{9}$ Though we do not report the results in the paper, we perform both Beaulieu and Miron (1993) and Robinson (1994) approaches, and we found in both cases strong evidence of unit roots with respect to the two series. Thus, since the two series are based on logarithm

\footnotetext{
shape of the impulse responses (Faust, 1998); via heteroskedasticity (Rigobon, 2003); or the use of highfrequency data (Faust, Swanson and Wright, 2004).

${ }^{9}$ See Gil-Alana and Robinson (2001) and Gil-Alana (2002, 2005) for descriptions of seasonal fractional models.
} 
transformations, in what follows we work with the monthly growth rate series, which is just the monthly first differences of the log-transformed data.

\section{INSERT FIGURE 2 ABOUT HERE}

Figure 2 displays the two monthly differenced log-transformed series with their corresponding correlograms and periodograms. It is observed that the two series may now present a stationary behaviour.

\subsection{Univariate results}

First we examine individually each series to check if they are truly stationary $\mathrm{I}(0)$. Here we employ a simple version of Robinson's (1994) univariate tests, which is based on the model,

$$
(1-L)^{d} y_{t}=u_{t}, \quad t=1,2, \ldots
$$

with $\mathrm{I}(0) \mathrm{u}_{\mathrm{t}}$. This method consists of testing the null hypothesis of

$$
H_{o}: d=d_{o}
$$

in (11) for any real value $d_{0}$. Thus, the unit root null hypothesis corresponds to

$$
H_{o}: d=1
$$

while $d=0$ corresponds to the stationary $\mathrm{I}(0)$ case. This method has some advantages compared with other more classic approaches of testing unit roots (Dickey and Fuller, 1979; Phillips and Perron, 1988; or any of its recent developments, Elliot et al., 1996; $\mathrm{Ng}$ and Perron, 2001, etc.). The most obvious one is clearly the fact that the latter approaches are too restrictive in relation with the order of integration since only $\mathrm{I}(0)$ and I(1) specifications are taken into account. Moreover, these methods are based on autoregressive (AR) alternatives, which in the simplest form, can be expressed as: 


$$
(1-\rho L) y_{t}=u_{t}
$$

testing the null of:

$$
H_{o}: \rho=1,
$$

in (14), and leading to a non-standard limit distribution, unlike what happens in Robinson, (1994) where the limit distribution is standard normal. Fractional and AR departures from (13) and (15) have very different long run implications. In (11), $\mathrm{y}_{\mathrm{t}}$ is nonstationary but non-explosive for all $\mathrm{d} \geq 0.5$. As $\mathrm{d}$ increases beyond 0.5 and through $1, \mathrm{y}_{\mathrm{t}}$ can be viewed as becoming "more nonstationary", but it does so gradually, unlike in case of (15) around (14). The dramatic long-run change in (14) around $\rho=1$ has the attractive implication that rejection of (15) can be interpreted as evidence of either stationarity or explosivity. However, rejection of the null does not necessarily warrant acceptance of any particular alternative and they can be consistent against many of the numerous other types of departure (Robinson, 1993). On the other hand, the approach employed here applies equally to any real null hypothesized value of $d$ and the same standard, null and local limit distribution theory obtains. This is also in sharp contrast to asymptotic theory for statistics directed against AR alternatives, where, for example, different null theory obtains for I(2) than for I(1) processes.

We use Robinson's (1994) approach, testing $\mathrm{H}_{\mathrm{o}}$ (12) in model (11) for $\mathrm{d}_{\mathrm{o}}$-values from -1 to 2 with 0.01 increments. Table 1 presents the values of $d_{o}$ where $H_{o}(12)$ cannot be rejected at the $5 \%$ level, for the two series assuming that $\mathrm{u}_{t}$ in (11) is first white noise, and then allowing for some type of weak dependence structure, in particular, AR(1) and Bloomfield-type disturbances. ${ }^{10}$ Moreover, we also permit the inclusion of an intercept and/or a linear time trend, and thus, we report the results for the three cases of no deterministic terms, an intercept and an intercept with a linear trend. 


\section{INSERT TABLE 1 ABOUT HERE}

Starting with the arrivals, the first thing we observe in Table 1 is that the two null hypotheses of $d=0$ and $d=1$ are both rejected in practically all cases, and the nonrejection values of $d$ are constrained between these two values. We also display in the table the value of $d$ producing the lowest statistic (in absolute value). That value should be an approximation to the maximum likelihood estimate of d since Robinson's (1994) method is based on the Whittle function, which is an approximation to the likelihood function. We observe that $\mathrm{d}$ is equal to 0.54 in case of white noise disturbances, and it is slightly higher for autocorrelated $\mathrm{u}_{\mathrm{t}}$. However, a very different picture is obtained for the export series. Thus, if $\mathrm{u}_{\mathrm{t}}$ is white noise, $\mathrm{d}$ seems to be slightly above 0 , and if autocorrelation is permitted, the null of $\mathrm{I}(0)$ stationarity cannot be rejected. Thus, it seems clear that the arrivals present a stronger degree of association across time and thus, a higher degree of persistency than the corresponding export series.

The results presented so far may be biased because of the presence of a structural break in the data. (See, again Figure 2). Gourieroux and Jasiak (2001), Diebold and Inoue (2001), Granger and Hyung (2004) and others showed that I(d) models and structural change are issues which are highly connected. Thus, we also perform another recent procedure (Gil-Alana, 2007) that permits us to estimate the fractional differencing parameters and the coefficients associated to the linear trend, along with the time of the structural break in a model given by:

$$
y_{t}=\alpha_{1}+\beta_{1} t+x_{t} ; \quad(1-L)^{d_{1}} x_{t}=u_{t}, \quad t=1, \ldots, T_{b}
$$

\footnotetext{
${ }^{10}$ The Bloomfield (1973) model is a non-parametric approach of modelling the $\mathrm{I}(0)$ disturbances that produces autocorrelations decaying exponential as in the AR(MA) case.
} 


$$
y_{t}=\alpha_{2}+\beta_{2} t+x_{t} ; \quad(1-L)^{d_{2}} x_{t}=u_{t}, \quad t=T_{b}+1, \ldots, T,
$$

where the $\alpha$ 's and the $\beta$ 's are the coefficients corresponding to the intercept and the linear trend; $d_{1}$ and $d_{2}$ may be real values, $u_{t}$ is again $I(0)$ and $T_{b}$ is the time of the break that is supposed to be unknown. Note that the model in (16) and (17) can also be written as:

$$
\begin{gathered}
(1-L)^{d_{1}} y_{t}=\alpha_{1} \tilde{1}_{t}\left(d_{1}\right)+\beta_{1} \tilde{t}_{t}\left(d_{1}\right)+u_{t}, \quad t=1, \ldots, T_{b}, \\
(1-L)^{d_{2}} y_{t}=\alpha_{2} \tilde{1}_{t}\left(d_{2}\right)+\beta_{2} \tilde{t}_{t}\left(d_{2}\right)+u_{t}, \quad t=T_{b}+1, \ldots, T,
\end{gathered}
$$

where $\tilde{1}_{t}\left(d_{i}\right)=(1-L)^{d_{i}} 1$, and $\tilde{\mathrm{t}}_{\mathrm{t}}\left(\mathrm{d}_{\mathrm{i}}\right)=(1-\mathrm{L})^{\mathrm{d}_{\mathrm{i}}} \mathrm{t}, \mathrm{i}=1,2$.

The procedure employed here is based on the least square principle and is similar to the one proposed by Bai and Perron (1998) for the case of stationary $\mathrm{I}(0)$ processes. First we choose a grid for the values of the fractionally differencing parameters $d_{1}$ and $d_{2}$, for example, $d_{i o}=0,0.01,0.02, \ldots, 1, i=1,2$. Then, for a given partition $\left\{T_{b}\right\}$ and given initial $d_{1}, d_{2}$-values, $\left(d_{10}^{(1)}, d_{20}^{(1)}\right)$, we estimate the $\alpha$ 's and the $\beta$ 's by minimizing the sum of squared residuals,

$$
\begin{array}{r}
\min \sum_{t=1}^{T_{b}}\left[(1-L)^{d_{1 o}^{(1)}} y_{t}-\alpha_{1} \tilde{1}_{t}\left(d_{1 o}^{(1)}\right)-\beta_{1} \tilde{t}_{t}\left(d_{1 o}^{(1)}\right)\right]^{2}+ \\
\text { w.r.t. }\left\{\alpha_{1}, \alpha_{2}, \beta_{1}, \beta_{2}\right\} \\
\sum_{t=T_{b}+1}^{T}\left[(1-L)^{d_{2 o}^{(1)}} y_{t}-\alpha_{2} \tilde{1}_{t}\left(d_{2 o}^{(1)}\right)-\beta_{2} \tilde{t}_{t}\left(d_{2 o}^{(1)}\right)\right]^{2}
\end{array}
$$

Let $\hat{\alpha}\left(\mathrm{T}_{\mathrm{b}} ; \mathrm{d}_{1 \mathrm{o}}^{(1)}, \mathrm{d}_{2 \mathrm{o}}^{(1)}\right)$ and $\hat{\beta}\left(\mathrm{T}_{\mathrm{b}} ; \mathrm{d}_{10}^{(1)}, \mathrm{d}_{2 \mathrm{o}}^{(1)}\right)$ denote the resulting estimates for partition $\left\{\mathrm{T}_{\mathrm{b}}\right\}$ and initial values $\mathrm{d}_{1 \mathrm{o}}^{(1)}$ and $\mathrm{d}_{2 \mathrm{o}}^{(1)}$. Substituting these estimated values on the objective function, we have $\operatorname{RSS}\left(\mathrm{T}_{\mathrm{b}} ; \mathrm{d}_{1 \mathrm{o}}^{(1)}, \mathrm{d}_{2 \mathrm{o}}^{(1)}\right)$, and minimizing this expression across all values of $d_{1 o}$ and $d_{2 o}$ in the grid we obtain $\operatorname{RSS}\left(T_{b}\right)=\arg \min _{\{i, j\}} \operatorname{RSS}\left(T_{b} ; d_{1 o}^{(i)}, d_{2 o}^{(j)}\right)$. 
Then, the estimated break date, $\hat{\mathrm{T}}_{\mathrm{k}}$, is such that $\hat{\mathrm{T}}_{\mathrm{k}}=\arg \min _{\mathrm{i}=1, \ldots, \mathrm{m}} \operatorname{RSS}\left(\mathrm{T}_{\mathrm{i}}\right)$, where the minimization is taken over all partitions $T_{1}, T_{2}, \ldots, T_{m}$, such that $T_{i}-T_{i-1} \geq|\varepsilon T|$. Then, the regression parameter estimates are the associated least-squares estimates of the estimated k-partition, i.e., $\hat{\alpha}_{i}=\hat{\alpha}_{i}\left(\left\{\hat{T}_{k}\right\}\right), \hat{\beta}_{i}=\hat{\beta}_{i}\left(\left\{\hat{T}_{k}\right\}\right)$, and their corresponding differencing parameters are $\hat{\mathrm{d}}_{\mathrm{i}}=\hat{\mathrm{d}}_{\mathrm{i}}\left(\left\{\hat{\mathrm{T}}_{\mathrm{k}}\right\}\right)$, for $\mathrm{i}=1$ and 2. Several Monte Carlo experiments conducted in Gil-Alana (2007) show that this procedure performs relatively well even with small samples. This procedure can be easily extended to the case of multiple breaks. However, for the validity of the type of long-memory (fractional integration) model we use in this application it is necessary that the data span a sufficiently long period of time to detect the dependence across time of the observations; given the sample size of the series employed here, the inclusion of two or more breaks would result in relatively short sub-samples, therefore invalidating the analysis based on fractional integration.

\section{INSERT TABLE 2 ABOUT HERE}

The results based on the above approach are displayed in Table 2. Starting with the arrivals, we observe that the break date takes place at 2001M1, which is surprisingly a few months earlier than the September $11^{\text {th }}$ attack in the U.S., and this happens for the two cases of white noise and $\operatorname{AR}(1)$ disturbances. If $u_{t}$ is white noise, the orders of integration are 0.58 and 0.21 respectively for the first and second sub-samples, and the $\mathrm{I}(0)$ hypothesis (i.e., $d=0$ ) is rejected in the two cases. If $u_{t}$ is $\operatorname{AR}(1)$ the orders of integration are again statistically higher than 0 , and are slightly higher in the two subsamples though again decreasing after the time break. If we concentrate now on the exports we observe that the break date occurs two months later than in the previous case 
(2001M3) and the orders of integration are 0.26 and -0.04 with uncorrelated errors and 0.31 and 0.02 with $\operatorname{AR}(1)$ disturbances. Here, the $\mathrm{I}(0)$ hypothesis is rejected in the first subsample but cannot be rejected after the break.

The finding of the break in the arrivals at 2001M1 may be explained by the fact that during 2000 the German economy slowed down significantly after the bursting of the technology bubble at the end of 1999 . Thus, from the beginning of 2001 there was a significant decrease in German international travel activities, in particular to Spain, the most important travel destination of Germans (Provincial Tourist Board of the Costa del Sol, 2003).

In sum, the results presented so far indicate that the two series display different orders of integration, independently of the inclusion or not of a structural break. In what follows we consider a bivariate set-up that solves the potential problems of unbalanced orders of integration in standard time series regression frameworks as is the case in the present work.

\subsection{Multivariate results}

In this section we look at the multivariate model. This is important if we want to determine the effect of structural shocks on the dynamic path of travelling and export trade variables. The bivariate model is estimated following the procedure in Gil-Alana (2003a). This method is briefly described in Appendix A and present two main advantages. First, it is an extension of the univariate tests of Robinson (1994) to the multivariate case and thus, similarly to the univariate case, we do not need to impose a priori any assumption about the orders of integration of the series as is the case with other approaches (e.g., Nielsen, 2004) or with standard VAR models. Second, with 
respect to the univariate case the orders of integration are estimated more efficiently since it makes use of additional information from the cross dependencies between the variables.

We estimate the orders of integration from the reduced form model (7), which, in this bivariate case, becomes:

$$
\left(\begin{array}{cc}
(1-L)^{d_{1}} & 0 \\
0 & (1-L)^{d_{2}}
\end{array}\right)\left(\begin{array}{l}
y_{1, t} \\
y_{2, t}
\end{array}\right)=\left(\begin{array}{l}
\varepsilon_{1, t} \\
\varepsilon_{2, t}
\end{array}\right), \quad t=1,2, \ldots
$$

where $\mathrm{y}_{1, \mathrm{t}}$ refers to the arrivals monthly growth series and $\mathrm{y}_{2, \mathrm{t}}$ is the monthly growth rate of exports, and test the null hypothesis:

$$
H_{o}: d \equiv\left(d_{1}, d_{2}\right)^{T}=\left(d_{1 o}, d_{2 o}\right)^{T} \equiv d_{o}
$$

in (20) for $\left(\mathrm{d}_{10}, \mathrm{~d}_{20}\right)$-values from -1 to 2 , with 0.01 increments, with $\varepsilon_{\mathrm{t}}=\left(\varepsilon_{1, \mathrm{t}}, \varepsilon_{2, \mathrm{t}}\right)^{\mathrm{T}}$ assumed to be first a white noise vector process, and later a VAR(1) specification. ${ }^{11}$ In order to avoid the inclusion of deterministic terms in (20) both series are meansubstracted before the implementation of the procedure.

\section{INSERT FIGURES 3 AND 4 ABOUT HERE}

Figures 3 and 4 display the region of $\left(\mathrm{d}_{10}, \mathrm{~d}_{20}\right)$-values where the null hypothesis (21) cannot be rejected at the 5\% level, letting the residuals to follow first (in Figure 3) a white noise vector process, and, in Figure 4, a stationary VAR(1) specification. Starting with the white noise model, we observe that the results are completely in line with the univariate ones. Thus, $\mathrm{d}_{1}$, the order of integration of the number of arrivals is constrained between 0.5 and 0.7 , while $\mathrm{d}_{2}$, the order of integration of the export series is

\footnotetext{
${ }^{11}$ Note that a non-diagonal matrix in (20) would lead to the analysis of fractional cointegration, which is an area of research that has received increasing attention in recent years. (See Gil-Alana and Hualde, 2008 , for a review).
} 
strictly above 0 , widely ranging between 0.05 and 0.45 . If we permit a VAR specification on the differenced series, the values of $d_{1}$ range between 0.5 and 1.2 , while those of $\mathrm{d}_{2}$ are constrained between -0.1 and $0.3{ }^{12}$

Table 4 identifies the estimates of the orders of integration of the two series, which are the values of $d_{1}$ and $d_{2}$ producing the lowest statistics in the multivariate procedure. We observe that if $u_{t}$ is white noise, the values are 0.54 and 0.18 respectively for the arrivals and exports. Imposing a VAR(1) specification, the values become 0.70 and $0.04 .^{13}$

\section{INSERT TABLE 4 ABOUT HERE}

The next step in our analysis is to report the associated impulse response function of exports to a shock in the travelling series. For this purpose we employ the two identification strategies described in Section 2, which, for the bivariate case is fully presented in Appendix B.

\section{INSERT TABLE 5 AND FIGURE 5 ABOUT HERE}

Table 5 and Figure 5 display the cross impulse responses of the effect of 1-unit shock in the growth rate of travelling on the growth rate of exports according to the two specifications described above, that is, the one based on white noise and the VAR(1) model. In both cases, for identification purposes, we first assume that $\mathrm{c}=0$ in equation (B1) (Appendix B), implying that there are nor contemporaneous neither future effects

\footnotetext{
${ }^{12}$ Similar results were obtained when using higher VAR orders for the disturbance term.
} 
of exports on travelling. Nevertheless, in the final part of this section, we also conduct the analysis using an additional identification schedule based on the Blanchard and Quah (1989) decomposition. ${ }^{14}$ We observe that according to the white noise specification, an increase in travelling produces a negative (though statistically insignificant) initial impact though it becomes positive for the following period and then, start decreasing fast. On the other hand, if we employ the VAR(1) specification, which seems to be a much more realistic assumption, the initial impact is positive (and significant) and then decreases at a lower rate than in the previous case of white noise disturbances. $^{15}$

\section{INSERT FIGURE 6 ABOUT HERE}

In the final part of this section we focus on the identification using the decomposition method proposed by Blanchard and Quah (1989). The impulse response functions, for the two cases of white noise and VAR(1) disturbances, are displayed in Figure 6. These confidence intervals were computed from 1,000 Monte Carlo draws of the estimated model using normally distributed errors. The results are fairly similar to those displayed in Figure 5 and based on the triangular identification. Thus, assuming white noise errors, the initial impact is negative though insignificantly different from zero, and using VAR disturbances, the effect is positive and significant for the initial periods, decreasing then fast to zero, implying that travelling produces a positive effect

\footnotetext{
${ }^{13}$ Standard F-tests were conducted in the VAR(1) specification and we could not reject the null hypothesis of no serial correlation. A Likelihood Ratio test also produced evidence for the VAR(1) against the $\operatorname{VAR}(2)$ model.

${ }_{14}^{14}$ Furthermore, and following the recommendations in Sims (1981) (see, also Lutkepohl and Breitung, 1996) we also checked whether the results were robust to the ordering of the variables. Altering the order of the variables the results for the impulse responses were practically identical to those reported in Figure 4.

${ }^{15}$ The confidence intervals here were obtained based on the asymptotic theory for multivariate fractional processes. (See, Nielsen, 2004).
} 
on exports at least for the case of the Spanish wine exports to Germany with respect to the German travellers to Spain.

\section{Comparison of the results to those of other studies}

Our results imply that, for the more realistic case of the VAR(1), in the event of a shock in travelling almost $10 \%$ of its effect on exports remains in the following period, though then decreases to $2.76 \%, 0.79 \%, 0.33 \%$ etc. (see Table 5). Overall, the total effect sums up to $14.7 \%$ over the tracked 20 months. However, $90 \%$ of this total effect is already realised after four months, and $95 \%$ of it after 9 months. These results seem to be in line with those obtained by Fischer and Gil-Alana (2007) who find (using long memory regressions and very similar monthly growth rate data) that the tourism-trade effect lasts two months (in the case of white noise disturbances) and 9 months in the case of Bloomfield $(\mathrm{p}=1)$ disturbances. However, the present study outperforms Fischer and Gil-Alana (2007) not only in the longer time period examined but also in the methodology employed that permits us to examine the cross impulse responses from a multivariate model.

\section{Concluding comments}

In this article we have examined the relationship between international trade and travelling. For this purpose we have focussed on a particular case study, analyzing the connections between the exports of Spanish wines to Germany with the total number of German travellers to Spain. We have employed a methodology based on fractional vector autoregressive models, which is more general than the standard VAR approach in the sense that we do not restrict the series to be $\mathrm{I}(0)$ or $\mathrm{I}(1)$ but $\mathrm{I}(\mathrm{d})$ for any real value $\mathrm{d}$. Starting from a structural model we have derived the conditions to identify the 
parameters from the reduced form model, which is basically a generalization of the standard I(0)/I(1) VAR case. The impulse response functions are then immediately obtained.

The series under analysis were the exports of Spanish wine to Germany and the total number of arrivals of Germans to Spain, monthly, from 1995M1 to 2006M7, both in logarithm form. Due to the nonstationary seasonal nature observed in the two series, first seasonal differences were adopted, working then with the monthly growth rates. The univariate work showed that the two series display different orders of integration. Thus, the arrivals present an order of integration which is constrained between 0.5 and 1 , while the degree of integration of exports is slightly above 0 . The multivariate work confirms that result and the impulse response analysis suggests that a positive shock in the arrivals tends to increase the exports to a certain level, decreasing then slowly the effect in the long run.

There are several contributions of the present work. In terms of new results, we provide further evidence of the relationship between Spanish wine exports to Germany and German travellers to Spain, noting that there are no previous results based on multivariate (fractional) impulse response functions. The obtained results are in line with earlier studies and thus add to the literature dealing with the tourism-trade relationship. While econometric findings in themselves cannot incontestably prove that a positive relationship between international travel activities and resulting trade flows exists in reality, the increasing body of empirical results clearly suggest that the existence of such a link may not be unlikely, at least for some products and in some countries.

Methodological innovations are the following: first, we extend fractional integration to the multivariate case, which has not yet been implemented in the 
empirical work. Second, the use of a structural fractional VAR model and the detailed description of the restrictions required for the identification of the system is the other methodological contribution of the paper. Finally, compared with Fischer and Gil-Alana (2007) the superiority of the presented technique is evident from the facts that first we extend the time period examined both backwards and forwards. Second, we use multivariate rather than univariate models with the incorporation of additional information through the variance-covariance matrices, and third we display impulse response functions that, in the context of multivariate systems permits us to examine the influence of one of the variables over the other.

Nevertheless, as argued above, there might be other factors that could have an influence in the relationship between German travellers to Spain and Spanish wine exports to Germany (for instance, a depreciation of the Spanish peseta vis-à-vis the German mark in the pre-EMU period would facilitate Spanish wine exports). These factors may have altered the relationship between the two variables and noting that fractional integration and structural breaks are issues which are intimately related, the inclusion of a structural break in our fractional VAR set-up seems mandatory in future work. Further work also needs to aim at establishing a theoretical economic framework (perhaps along the lines of Fischer, 2007), which can contribute to explain the existence of the tourism-trade phenomenon. 


\section{Appendix A}

A simple version of the procedure proposed in Gil-Alana (2003a,b) consists of testing the null hypothesis:

$$
H_{o}: d \equiv\left(d_{1}, d_{2}, \ldots, d_{n}\right)^{T}=\left(d_{1 o}, d_{2 o}, \ldots, d_{n o}\right)^{T} \equiv d_{o}
$$

for any real vector $d_{0}$, in the model given by (7) where $\varepsilon_{t}$ is supposed to be an $\mathrm{I}(0)$ vector process with spectral density function $F(\lambda)$ that is positive definite. Thus $\varepsilon_{t}$ may be white noise but it also allows us to include VAR structures. To allow for some degree of generality, let us suppose that $\varepsilon_{\mathrm{t}}$ in (7) is generated by a parametric model of form:

$$
\varepsilon_{t}=\sum_{j=0}^{\infty} A_{j}(\tau) w_{t-j}, \quad t=1,2, \ldots
$$

where $\mathrm{w}_{\mathrm{t}}$ is white noise and $\mathrm{W}$ is the unknown variance-covariance matrix of $\mathrm{w}_{\mathrm{t}}$. The spectral density matrix of $\varepsilon_{\mathrm{t}}$ is then

$$
f(\lambda ; \tau)=\frac{1}{2 \pi} w(\lambda ; \tau) W w(\lambda ; \tau)^{*}
$$

where $w(\lambda ; \tau)=\sum_{j=0}^{\infty} A_{j}(\tau) e^{i \lambda j}$, and $\mathrm{w}^{*}$ means the complex-conjugate transpose of $\mathrm{w}$. A number of conditions are required on $A$ and $f_{\varepsilon}$ when deriving the test statistic; their practical implications being that though $\varepsilon_{\mathrm{t}}$ is capable of exhibiting a much stronger degree of autocorrelation than multiple ARMA processes, its spectral density matrix must be finite, with eigenvalues bounded and bounded away from zero. In Gil-Alana (2003a) it is shown that a Lagrange Multiplier (LM) test of $H_{o}$ (A1) in (7) takes the form:

$$
\tilde{S}=T \tilde{b}^{T}\left[\tilde{C}-\tilde{D}^{T} \tilde{E}^{-1} \tilde{D}\right]^{-1} \tilde{b}
$$

where $\mathrm{T}$ is the sample size and 


$$
\begin{gathered}
\tilde{b}=\frac{-1}{T} \sum_{r=1}^{T-1} \psi\left(\lambda_{r}\right) \operatorname{tr}\left(I_{\varepsilon}\left(\lambda_{r}\right) \tilde{f}\left(\lambda_{r} ; \tilde{\tau}\right) ; \quad \tilde{C}=\frac{4}{T} \sum_{r=1}^{T-1} \psi\left(\lambda_{r}\right) \psi\left(\lambda_{r}\right)^{T} ;\right. \\
\tilde{D}^{T}=\frac{-1}{T} \sum_{r=1}^{T-1} \psi\left(\lambda_{r}\right)\left[\operatorname{tr}\left(\tilde{f}^{-1}\left(\lambda_{r} ; \tilde{\tau}\right) \frac{\partial \tilde{f}\left(\lambda_{r} ; \tilde{\tau}\right)}{\partial \tau_{1}}\right) ; \ldots ; \operatorname{tr}\left(\tilde{f}^{-1}\left(\lambda_{r} ; \tilde{\tau}\right) \frac{\left.\partial \tilde{f}\left(\lambda_{r} ; \tilde{\tau}\right)\right)}{\partial \tau_{q}}\right)\right] ; \\
\tilde{E}_{u v}=\frac{1}{2 T} \sum_{r=1}^{T-1} \operatorname{tr}\left(\tilde{f}^{-1}\left(\lambda_{r} ; \tilde{\tau}\right) \frac{\partial \tilde{f}\left(\lambda_{r} ; \tilde{\tau}\right)}{\partial \tau_{u}} \tilde{f}^{-1}\left(\lambda_{r} ; \tilde{\tau}\right) \frac{\partial \tilde{f}\left(\lambda_{r} ; \tilde{\tau}\right)}{\partial \tau_{v}}\right),
\end{gathered}
$$

where $\mathrm{I}_{\varepsilon}\left(\lambda_{\mathrm{r}}\right)$ is a matrix with $(\mathrm{u}, \mathrm{v})^{\text {th }}$ element:

$$
\begin{gathered}
I_{u v}\left(\lambda_{r}\right)=W_{u}\left(\lambda_{r}\right) \bar{W}_{v}\left(\lambda_{r}\right) ; \quad W_{u}\left(\lambda_{r}\right)=\frac{1}{\sqrt{2 \pi T}} \sum_{t=1}^{T} \widetilde{\varepsilon}_{u t} e^{i \lambda_{r} t}, \\
\tilde{\varepsilon}=\left(\begin{array}{l}
\widetilde{\varepsilon}_{1 t} \\
-- \\
\widetilde{\varepsilon}_{n t}
\end{array}\right)=\left(\begin{array}{ccc}
(1-L)^{d_{1 o}} & -- & -- \\
& -- & \\
-- & -- & (1-L)^{d_{n o}}
\end{array}\right)\left(\begin{array}{l}
y_{1 t} \\
-- \\
y_{n t}
\end{array}\right),
\end{gathered}
$$

where the line over $\mathrm{W}$ denotes complex conjugate, and $\tilde{f}$ is the spectral density matrix of $\widetilde{\varepsilon}$ :

$$
\tilde{f}(\lambda ; \tau)=\frac{1}{2 \pi} \widetilde{w}(\lambda ; \tau) \widetilde{W} \widetilde{w}(\lambda ; \tau)^{*}
$$

with

$$
\tilde{w}(\lambda ; \tau)=\sum_{j=0}^{\infty} A_{j}(\tau) \tilde{\varepsilon}^{i \lambda j} \text { and } \tilde{W}=\frac{1}{T} \sum_{t=1}^{T} \widetilde{\varepsilon}_{t} \tilde{\varepsilon}_{t}^{T}
$$

Finally,

$$
\tilde{\tau}=\arg \min { }_{\tau \in T} *\left(\frac{T}{2} \log \operatorname{det} \tilde{f}\left(\lambda_{r} ; \tau\right)+\frac{1}{2} \sum_{r=1}^{T-1} \operatorname{tr}\left(\tilde{f}^{-1}\left(\lambda_{r} ; \tau\right) I_{\varepsilon}\left(\lambda_{r}\right)\right)\right),
$$

where $\mathrm{T}^{*}$ is a compact subset of q-dimensional Euclidean space. Extending the conditions in Robinson (1994), Gil-Alana (2003a) shows that:

$$
\tilde{S} \rightarrow_{d} \chi_{n}^{2} \quad \text { as } \quad T \rightarrow \infty
$$




\section{Appendix B}

We consider the following structural bivariate model:

$\left(\begin{array}{ll}a & b \\ c & d\end{array}\right)\left(\begin{array}{cc}(1-L)^{d_{1}} & 0 \\ 0 & (1-L)^{d_{2}}\end{array}\right)\left(\begin{array}{l}y_{1, t} \\ y_{2, t}\end{array}\right)=\left(\begin{array}{l}u_{1, t} \\ u_{2, t}\end{array}\right), \quad t=1,2, \ldots$

where, initially, $\mathrm{u}_{1, \mathrm{t}}$ and $\mathrm{u}_{2, \mathrm{t}}$ are assumed to be serially uncorrelated, mutually orthogonal structural disturbances, whose variances are normalized to unity. Note that this model can be expressed as:

$$
\left(\begin{array}{cc}
(1-L)^{d_{1}} & y_{1, t} \\
(1-L)^{d_{2}} & y_{2, t}
\end{array}\right)=\left(\begin{array}{c}
\frac{d}{a d-b c} u_{1, t}-\frac{b}{a d-b c} u_{2, t} \\
\frac{-c}{a d-b c} u_{1, t}+\frac{a}{a d-b c} u_{2, t}
\end{array}\right), \quad t=1,2, \ldots
$$

Considering now the transformed disturbances:

$$
u_{1, t}^{*}=\frac{1}{a d-b c}\left(d u_{1, t}-b u_{2, t}\right) \text { and } u_{2, t}^{*}=\frac{1}{a d-b c}\left(a u_{2, t}-c u_{1, t}\right) \text {, }
$$

and using the Binomial expansions in the fractional differencing polynomials in the lefthand-side of (B1), we obtain

$$
y_{1, t}=\sum_{j=0}^{\infty} \psi_{j}^{(1)} u_{1, t-j}^{*} \text { and } y_{2, t}=\sum_{j=0}^{\infty} \psi_{j}^{(2)} u_{2, t-j}^{*}
$$

where $\psi_{j}^{(i)}=\frac{\Gamma\left(j+d_{i}\right)}{\Gamma(j+1) \Gamma\left(d_{i}\right)}, \quad i=1,2$, and $\Gamma(\mathrm{x})$ stands for the Gamma function and $d_{i}, i=1,2$ are the orders of integration of the two series. Substituting (B3) into (B4):

$$
y_{1, t}=\sum_{j=0}^{\infty} \phi_{j}^{(1,1)} u_{1, t-j}+\sum_{j=0}^{\infty} \phi_{j}^{(1,2)} u_{2, t-j} ; y_{2, t}=\sum_{j=0}^{\infty} \phi_{j}^{(2,1)} u_{1, t-j}+\sum_{j=0}^{\infty} \phi_{j}^{(2,2)} u_{2, t-j}
$$

where the impulse response coefficients are:

$$
\phi_{\mathrm{j}}^{(1,1)}=\frac{\mathrm{d} \psi_{\mathrm{j}}^{(1)}}{\mathrm{ad}-\mathrm{bc}} ; \quad \phi_{\mathrm{j}}^{(1,2)}=\frac{-\mathrm{b} \psi_{\mathrm{j}}^{(1)}}{\mathrm{ad}-\mathrm{bc}} ; \quad \phi_{\mathrm{j}}^{(2,1)}=\frac{-\mathrm{c} \psi_{\mathrm{j}}^{(2)}}{\mathrm{ad}-\mathrm{bc}} ; \quad \phi_{\mathrm{j}}^{(2,2)}=\frac{\mathrm{a} \psi_{\mathrm{j}}^{(2)}}{\mathrm{ad}-\mathrm{bc}} .
$$




\section{Appendix B.1: $\quad$ Identification in a pure vector fractional model}

From the reduced-form system:

$$
\left(\begin{array}{cc}
(1-L)^{d_{1}} & 0 \\
0 & (1-L)^{d_{2}}
\end{array}\right)\left(\begin{array}{l}
y_{1, t} \\
y_{2, t}
\end{array}\right)=\left(\begin{array}{l}
\varepsilon_{1, t} \\
\varepsilon_{2, t}
\end{array}\right), \quad t=1,2, \ldots
$$

we can obtain the estimates of $d_{1}$ and $d_{2}$ under the assumption that $\varepsilon_{t}$ is a white noise vector process. Using now (B2) and (B7):

$\varepsilon_{1, t}=\frac{d}{a d-b c} u_{1, t}-\frac{b}{a d-b c} u_{2, t}, \quad$ and $\quad \varepsilon_{2, t}=\frac{-c}{a d-b c} u_{1, t}+\frac{a}{a d-b c} u_{2, t}$,

implying that

$$
\begin{aligned}
& \sigma_{11}^{\varepsilon}=\frac{1}{(a d-b c)^{2}}\left(d^{2} \sigma_{11}^{u}+b^{2} \sigma_{22}^{u}-2 b d \sigma_{12}^{u}\right), \\
& \sigma_{22}^{\varepsilon}=\frac{1}{(a d-b c)^{2}}\left(c^{2} \sigma_{11}^{u}+a^{2} \sigma_{22}^{u}-2 a c \sigma_{12}^{u}\right), \\
& \sigma_{12}^{\varepsilon}=\frac{1}{(a d-b c)^{2}}\left((a d+b c) \sigma_{12}^{u}-d c \sigma_{11}^{u}-a b \sigma_{22}^{u}\right)
\end{aligned}
$$

Note that in this context we have three equations (B8-B10) for seven unknowns (a, b, c, $\mathrm{d}, \sigma_{11}^{u}, \sigma_{12}^{u}$ and $\sigma_{22}^{u}$ ), but using the restrictions imposed on the variance-covariance matrix of $\mathrm{u}_{\mathrm{t}}\left(\sigma_{12}^{u}=0\right.$ and $\left.\sigma_{11}^{u}=\sigma_{22}^{u}=1\right)$, the system given by $(\mathrm{B} 8)-(\mathrm{B} 10)$ reduces to:

$$
\sigma_{11}^{\varepsilon}=\frac{1}{(\mathrm{ad}-\mathrm{bc})^{2}}\left(\mathrm{~d}^{2}+\mathrm{b}^{2}\right) ; \quad \sigma_{22}^{\varepsilon}=\frac{1}{(\mathrm{ad}-\mathrm{bc})^{2}}\left(\mathrm{a}^{2}+\mathrm{c}^{2}\right), \quad \sigma_{12}^{\varepsilon}=\frac{-1}{(a d-b c)^{2}}(d c+a b) .
$$

The new system of equations is still not identified, as there are only three equations for four unknowns. One possibility is to assume that one of the coefficients $(\mathrm{a}, \mathrm{b}, \mathrm{c}$ or $\mathrm{d})$ is equal to 0 . For example, $\mathrm{b}=0$ implies, according to (B6), that $\mathrm{a}$ structural shock to $\mathrm{y}_{2 \mathrm{t}}\left(\mathrm{u}_{2 \mathrm{t}}\right)$ has no effect on $\mathrm{y}_{1 \mathrm{t}}$ neither contemporaneously nor in the long run. Similarly, if $\mathrm{c}=0$, a shock to $\mathrm{y}_{1 \mathrm{t}}$ will have no effect on $\mathrm{y}_{2 \mathrm{t}}$. This is a plausible 
assumption in some cases. Alternatively, (Blanchard and Quah, 1989) we can impose the restriction:

$$
\sum_{j=0}^{\infty} \phi_{j}^{(1,2)}=0, \text { or } \sum_{j=0}^{\infty} \phi_{j}^{(2,1)}=0 \text {. }
$$

Combining the previous expression with (B11) the system is now completely identified and the impulse response functions can easily be obtained.

\section{Appendix B.2 A (2x1) vector fractionally autoregressive model}

Here, we extend the structural model (B1) to the case of weak parametric autocorrelation in $\mathrm{u}_{\mathrm{t}}$. In particular, we consider the case of a VAR(1) system for $\mathrm{u}_{\mathrm{t}}$. Thus, the structural model is now (B1) with

$$
\left(\begin{array}{l}
u_{1, t} \\
u_{2, t}
\end{array}\right)=\left(\begin{array}{ll}
\phi_{11} & \phi_{12} \\
\phi_{21} & \phi_{22}
\end{array}\right)\left(\begin{array}{l}
u_{1, t-1} \\
u_{2, t-1}
\end{array}\right)+\left(\begin{array}{l}
v_{1, t} \\
v_{2, t}
\end{array}\right), \quad t=1,2, \ldots
$$

where $\mathrm{v}_{1, \mathrm{t}}$ and $\mathrm{v}_{2, \mathrm{t}}$ are serially uncorrelated and mutually orthogonal with unit variance (i.e., $\sigma_{11}^{v}=\sigma_{22}^{v}=1$ and $\sigma_{12}^{v}=0$ ) and with all the roots lying outside the unit circle. First, we describe the impulse response functions. Assuming that $\mathrm{u}_{\mathrm{t}}$ is stationary, (B12) can be written as:

$$
\left(\begin{array}{l}
u_{1, t} \\
u_{2, t}
\end{array}\right)=\left(\begin{array}{ll}
C_{11}(L) & C_{12}(L) \\
C_{21}(L) & C_{22}(L)
\end{array}\right)\left(\begin{array}{c}
v_{1, t} \\
v_{2, t}
\end{array}\right), \quad t=1,2, \ldots,
$$

where $\mathrm{C}_{\mathrm{ij}}(\mathrm{L}), \mathrm{i}, \mathrm{j}=1,2$ are polynomials of infinite order in L. From (B2) and (B13):

$$
\begin{aligned}
& \left(\begin{array}{ll}
(1-L)^{d_{1}} & y_{1, t} \\
(1-L)^{d_{2}} & y_{2, t}
\end{array}\right)=\frac{1}{a d-b c}\left(\begin{array}{cc}
d & -b \\
-c & a
\end{array}\right)\left(\begin{array}{l}
C_{11}(L) v_{1, t}+C_{12}(L) v_{2, t} \\
C_{21}(L) v_{1, t}+C_{22}(L) v_{2, t}
\end{array}\right)= \\
& \frac{1}{a d-b c}\left(\begin{array}{l}
d C_{11}(L) v_{1, t}+d C_{12}(L) v_{2, t}-b C_{21}(L) v_{1, t}-b C_{22}(L) v_{2, t} \\
-c C_{11}(L) v_{1, t}-c C_{12}(L) v_{2, t}+a C_{21}(L) v_{1, t}+a C_{22}(L) v_{2, t}
\end{array}\right)=\left(\begin{array}{l}
w_{1, t} \\
w_{2, t}
\end{array}\right) .
\end{aligned}
$$

Hence, the model becomes: 


$$
\begin{aligned}
& \left(\begin{array}{ll}
(1-L)^{d_{1}} & y_{1, t} \\
(1-L)^{d_{2}} & y_{2, t}
\end{array}\right)=\left(\begin{array}{l}
w_{1, t} \\
w_{2, t}
\end{array}\right), \quad t=1,2, \ldots ., \text { implying that } \\
& y_{1, t}=\sum_{j=0}^{\infty} \psi_{j}^{(1)} w_{1, t-j} \text { and } \quad y_{2, t}=\sum_{j=0}^{\infty} \psi_{j}^{(2)} w_{2, t-j} .
\end{aligned}
$$

Substituting now $\mathrm{w}_{\mathrm{t}}$ from (B14) into (B15) we obtain

$$
\begin{aligned}
& y_{1, t}=\sum_{j=0}^{\infty} \rho_{j}^{(1,1)} v_{1, t-j}+\sum_{j=0}^{\infty} \rho_{j}^{(1,2)} v_{2, t-j}, \\
& y_{2, t}=\sum_{j=0}^{\infty} \rho_{j}^{(2,1)} v_{1, t-j}+\sum_{j=0}^{\infty} \rho_{j}^{(2,2)} v_{2, t-j},
\end{aligned}
$$

where the impulse response functions are:

$$
\begin{array}{ll}
\rho_{\mathrm{j}}^{(1,1)}=\psi_{\mathrm{j}}^{(1)} \frac{\left(\mathrm{dC}_{11}(\mathrm{~L})-\mathrm{bC}_{21}(\mathrm{~L})\right)}{\mathrm{ad}-\mathrm{bc}} ; & \rho_{\mathrm{j}}^{(1,2)}=\psi_{\mathrm{j}}^{(1)} \frac{\left(\mathrm{dC}_{12}(\mathrm{~L})-\mathrm{bC}_{22}(\mathrm{~L})\right)}{\mathrm{ad}-\mathrm{bc}} ; \\
\rho_{\mathrm{j}}^{(2,1)}=\psi_{\mathrm{j}}^{(2)} \frac{\left(-\mathrm{cC}_{11}(\mathrm{~L})+\mathrm{aC}_{21}(\mathrm{~L})\right)}{\mathrm{ad}-\mathrm{bc}} ; & \rho_{j}^{(2,2)}=\psi_{j}^{(2)} \frac{\left(-c C_{12}(L)+a C_{22}(L)\right)}{a d-b c} .
\end{array}
$$

\section{Appendix B.3 Identification in a VAR fractional model}

The reduced-form model is now (B7) with

$$
\left(\begin{array}{c}
\varepsilon_{1, t} \\
\varepsilon_{2, t}
\end{array}\right)=\left(\begin{array}{ll}
\xi_{11} & \xi_{12} \\
\xi_{21} & \xi_{22}
\end{array}\right)\left(\begin{array}{l}
\varepsilon_{1, t-1} \\
\varepsilon_{2, t-1}
\end{array}\right)+\left(\begin{array}{c}
w_{1, t} \\
w_{2, t}
\end{array}\right), \quad t=1,2, \ldots
$$

and using again any of the parametric procedures for vector fractional integration we can obtain estimates of $\mathrm{d}_{1}$ and $\mathrm{d}_{2}, \xi_{11}, \xi_{12}, \xi_{21}$ and $\xi_{22}$, along with the coefficients of the variance-covariance matrix of $\mathrm{w}_{\mathrm{t}}$, i.e., $\sigma_{11}^{w}, \sigma_{12}^{w}$ and $\sigma_{22}^{w}$.

Identification follows here the same lines as in the previous case, noting that

$$
\left(\begin{array}{l}
w_{1, t} \\
w_{2, t}
\end{array}\right)=\left(\begin{array}{ll}
a & b \\
c & d
\end{array}\right)^{-1}\left(\begin{array}{l}
v_{1, t} \\
v_{2, t}
\end{array}\right)
$$

implying three equations of the same form as in the white noise case, and that 


$$
\left(\begin{array}{ll}
\xi_{11} & \xi_{12} \\
\xi_{21} & \xi_{22}
\end{array}\right)=\left(\begin{array}{ll}
a & b \\
c & d
\end{array}\right)^{-1}\left(\begin{array}{ll}
\phi_{11} & \phi_{12} \\
\phi_{21} & \phi_{22}
\end{array}\right)\left(\begin{array}{ll}
a & b \\
c & d
\end{array}\right) .
$$

Thus, we add four equations with four unknowns, so the same restrictions as in the previous case apply here. 


\section{References}

Adenstedt, R.K., 1974, On large-sample estimation for the mean of a stationary random sequence, Annals of Statistics 2, 1095-1107.

Anderson, K., 2004, Introduction, in: The World's Wine Markets - Globalization at Work, K. Anderson (ed), Edward Elgar, Cheltenham, 3-13.

Aradhyula, S. and R. Tronstad, 2003, Does Tourism Promote Cross-Border Trade?, American Journal of Agricultural Economics 85, 569-579.

Assaf, A., 2007, Fractional integration in the equity markets of MENA region, Applied Financial Economics 17, 709-723.

Bai, J. and P. Perron, 1998, Estimating and testing linear models with multiple structural changes, Econometrica 66, 47-78.

Baillie, R.T., 1996, Long memory processes and fractional integration in econometrics, Journal of Econometrics 73, 5-59.

Baillie, R.T. and T. Bollerlev, 1994, The long memory of the forward premium, Journal of International Money and Finance 15, 565-571.

Barkoulas, J.T., C. Baum and M. Caglayan, 1999, Fractional monetary dynamics, Applied Economics 31, 1393-1400.

Beaulieu, J.J. and J.A. Miron, 1993, Seasonal unit roots in aggregate US data, Journal of Econometrics 55, 305-328.

Blanchard, O. and D. Quah, 1989, The dynamics effects of aggregate demand and supply disturbances, American Economic Review 79, 655-673.

Bloomfield, P., 1973, An exponential model in the spectrum of a scalar time series, Biometrika 60, 217-226. 
Dickey, D.A. and W.A. Fuller, 1979, Distributions of the estimators for autoregressive time series with a unit root, Journal of the American Statistical Association, 74, 427431.

Diebold, F.S. and A. Inoue, 2001, Long memory and regime switching. Journal of Econometrics, 105, 131-159.

Diebold, F.X. and G.D. Rudebusch, 1989, Long memory and persistence in aggregate output, Journal of Monetary Economics 24, 189-209.

Doukhan, P., G. Oppenheim and M.S. Taqqu, 2003, Theory and applications of long range dependence, Birkhäuser, Basel.

Easton, S. T., 1998, Is Tourism Just Another Commodity? Links between Commodity Trade and Tourism, Journal of Economic Integration 13, 522-543.

Elliot, G., J.H. Stock and T. Rothenberg, 1996, Efficient tests of an autoregressive unit root, Econometrica 64, 813-836.

Faust, J., 1998, The robustness of identified VAR conclusions about money, CarnegieRochester Conference Series on Public Policy 49, 207-244.

Faust, J., E. Swanson and J. Wright, 2004, Identifying VARs based on high frequency futures data, Journal of Monetary Economics 51, 1107-1131.

Felzenstein, C., S. Hibbert and G. Vong, 2004, Is the Country of Origin the Fifth Element in the Marketing Mix of Wine? A Critical Review of the Literature, Journal of Food Products Marketing 10, 73-84.

Fischer, C., 2004, The influence of immigration and international tourism on the demand for imported food products, Food Economics 1, 21-33.

Fischer, C., 2007, The influence of immigration and international tourism on the import demand for consumer goods - a theoretical model, in: Advances in Modern Tourism 
Research: Economic Perspectives, Á. Matias, P. Neto, P. Nijkamp (eds). PhysicaVerlag, Heidelberg, 37-50.

Fischer, C. and L.A. Gil-Alana, 2007, The Nature of the Relationship Between International Tourism and International Trade: the Case of German Imports of Spanish Wine, Applied Economics, forthcoming.

Gil-Alana, L.A., 2002, Seasonal long memory in the aggregate output, Economics Letters 74, 333-337.

Gil-Alana, L.A., 2003a, Multivariate tests of nonstationary hypotheses, South African Statistical Journal 37, 1-28.

Gil-Alana, L.A., 2003b, A fractional multivariate long memory model for the US and the Canadian real output, Economics Letters 81, 355-359.

Gil-Alana, L.A., 2005, Deterministic seasonality versus seasonal fractional integration, Journal of Statistical Planning and Inference 134, 445-461.

Gil-Alana, L.A., 2007, Fractional integration and structural breaks at unknown points in time, Journal of Time Series Analysis, forthcoming.

Gil-Alana, L.A. and P. Mendi, 2005, Fractional integration in total factor productivity: evidence from US data, Applied Economics 37, 1369-383

Gil-Alana, L.A. and J. Hualde, 2008, Fractional integration and cointegration. An overview and an empirical application, Palgrave Handbook of Econometrics, Vol. 2, forthcoming.

Gil-Alana, L.A. and P.M. Robinson, 1997, Testing of unit roots and other nonstationary hypotheses in macroeconomic time series, Journal of Econometrics 80, 241-268.

Gil-Alana, L.A. and P.M. Robinson, 2001, Testing seasonal fractional integration in the UK and Japansese consumption and income, Journal of Applied Econometrics 16. 95114. 
Gourieroux, C. and Jasiak, J., 2001, Memory and infrequent breaks, Economics Letters, 70, 29-41.

Granger, C.W.J., 1980, Long memory relationships and the aggregation of dynamic models, Journal of Econometrics 14, 227-238.

Granger, C.W.J., 1981, Some properties of time series data and their use in econometric model specification, Journal of Econometrics 16, 121-130.

Granger, C.W.J. and N. Hyung, 2004, Occasional structural breaks and long memory with an application to the S\&P 500 absolute stock returns. Journal of Empirical Finance $11,399-421$.

Granger, C.W.J. and R. Joyeux, 1980, An introduction to long memory time series and fractionally differencing, Journal of Time Series Analysis 1, 15-29.

Gschwandtner, A. and M.A. Hauser, 2007, Modelling profit series: nonstationarity and long memory, Applied Economics, 39, 1-8.

Hosking, J.R.M., 1981, Fractional differencing, Biometrika 68, 165-176.

Hylleberg, S., R. F. Engle, C. W. J. Granger and B. S. Yoo, 1990, Seasonal integration and cointegration, Journal of Econometrics 44, 215-238.

Johansen, S., 2006, A representation theory for a class of vector autoregressive models for fractional processes. Econometric Theory, forthcoming.

King, R.G., C.J. Plosser, J.H. Stock and M.W. Watson, 1991, Stochastic trends and economic fluctuations, American Economic Review 81, 819-840

Kulendran, N. and K. Wilson, 2000, Is there a relationship between international trade and international travel?, Applied Economics 32, 1001-1009.

Lutkepohl, H. and J. Breitung, 1997, Impulse response analysis of vector autoregressive processes, in Heij, C., Schumacher, H., Hanzon, B. and C. Praagman (eds.), System Dynamics in Economic and Financial Models, Ghichester John Wiley, 1997, 299-320. 
Mandelbrot, B., 1977, Fractals, form, chance and dimension. New York, Free Press.

Marinucci, D. and P.M. Robinson, 1999, Alternative forms of fractional Brownian motion, Journal of Statistical Planning and Inference 80, 111-122.

Nielsen, M.O., 2004, Efficient inference in multivariate fractionally integrated time series models. Econometrics Journal 7, 63-97.

Ng, S. and P. Perron, 2001, Lag length selection and the construction of unit root tests with good size and power, Econometrica 69, 1519-1554.

Nielsen, M.O., 2005, Multivariate Lagrange Multiplier tests for fractional integration, Journal of Financial Econometrics 3, 372-398.

Phillips, P.C.B. and P. Perron, 1988, Testing for a unit root in a time series regression, Biometrika 75, 335-346.

Provincial Tourist Board of the Costa del Sol, 2003, German market report ITB 2003, www.turismocostadelsol.org.

Rigobon, R., 2003, Identification through heteroskedasticity, Review of Economics and Statistics 85, 777-792.

Robinson, P.M., 1978, Statistical inference for a random coefficient autoregressive model, Scandinavian Journal of Statistics 5, 163-168.

Robinson, P.M., 1993, Highly insignificant F-ratios, Econometrica 61, 687-696.

Robinson, P.M., 1994, Efficient tests of nonstationary hypotheses, Journal of the American Statistical Association 89, 1420-1437.

Robinson, P.M., 2003. Long memory time series, in Time Series with Long Memory, (P.M. Robinson, ed.), Oxford University Press, Oxford, 1-48.

Shan, J. and K. Wilson, 2001, Causality Between Trade and Tourism: Empirical Evidence from China, Applied Economic Letters 8, 279-283.

Sims, C., 1980, Macroeconomics and Reality, Econometrica 48, 1-48. 
Sims, C., 1981, An autoregressive index model for the US: 1948-1975, in J. Kmenta \& J.B. Ramsey (eds.), Large-Scale Macro-Econometric Models, Amsterdam: North Holland, 283-327.

Taqqu, M.S., 1975, Weak convergence to fractional Brownian motion and to the Rosenblatt process, Z. Wahrscheinlichkeitstheorie verw. Geb. 31, 287-302.

Tolvi, J., 2003, Long memory and outliers in stock market returns, Applied Financial Economics 13, 495-502. 
Figures and tables

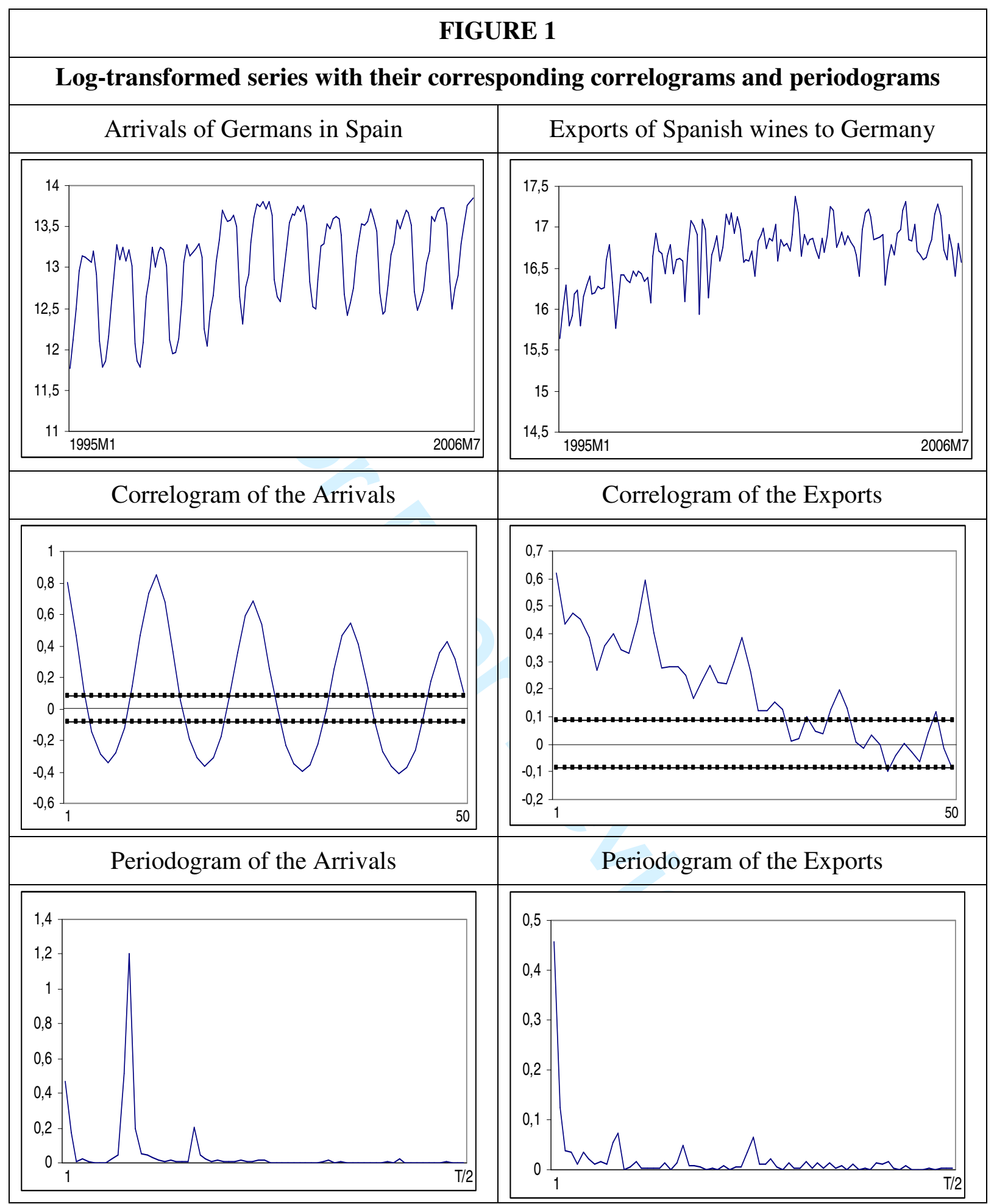

The large sample standard error under the null hypothesis of no autocorrelation is $1 / \sqrt{ } \mathrm{T}$ or roughly 0.08 for the series used in this application. The periodograms are computed based on the discrete frequencies $\lambda_{\mathrm{j}}=2 \pi \mathrm{j} / \mathrm{T}$. 


\section{FIGURE 2}

\section{Monthly growth rate series with their corresponding correlograms and periodograms}
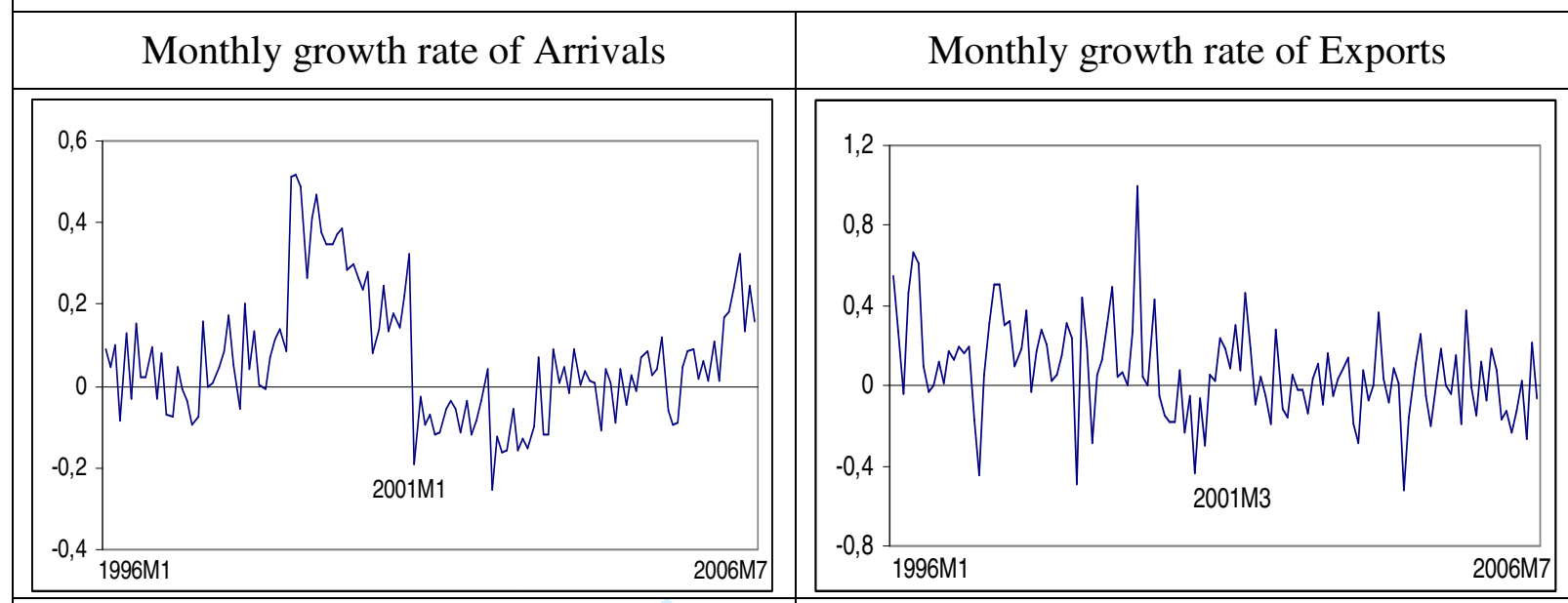

Correlogram monthly growth rate of arrivals

Correlogram monthly growth rate of exports
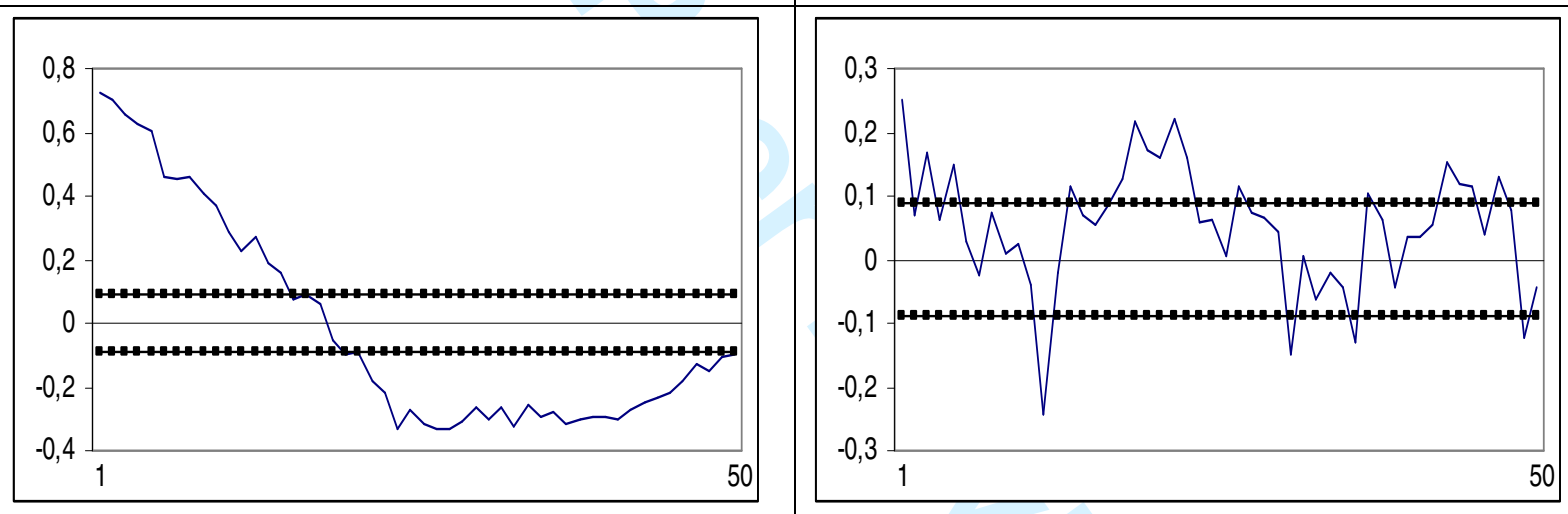

Periodogram monthly growth rate of arrivals

Periodogram monthly growth rate of exports
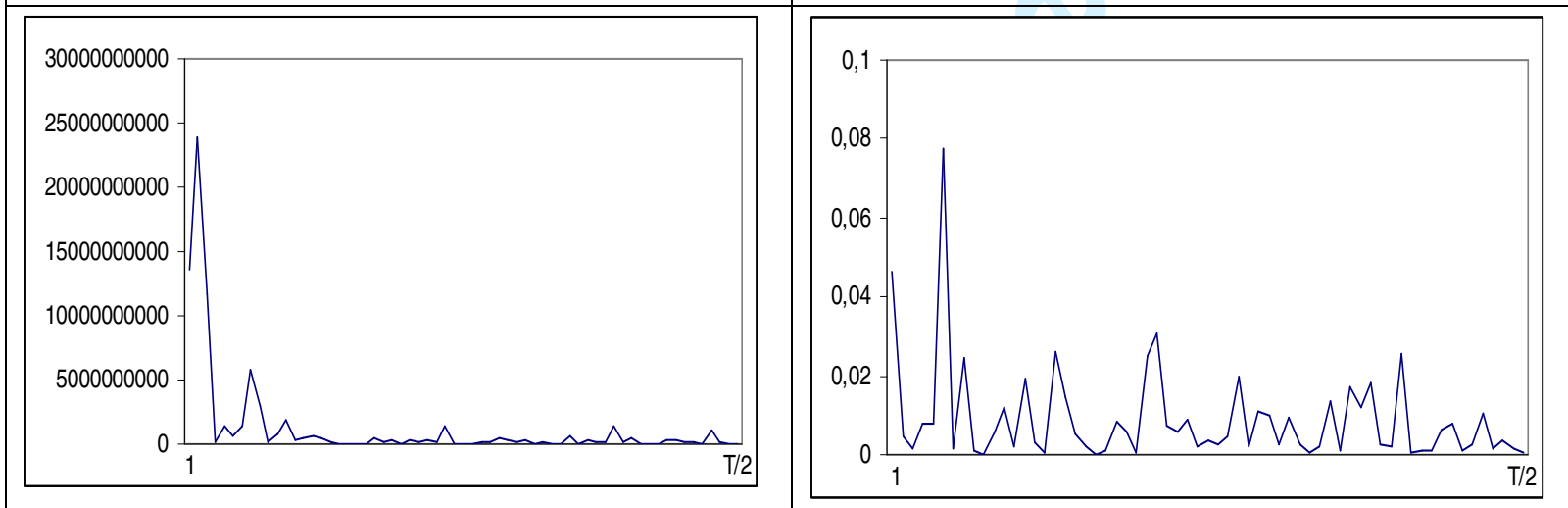

The large sample standard error under the null hypothesis of no autocorrelation is $1 / \sqrt{T}$ or roughly 0.08 for the series used in this application. The periodograms are computed based on the discrete frequencies $\lambda_{\mathrm{j}}=2 \pi \mathrm{j} / \mathrm{T}$. 


\begin{tabular}{|c|c|c|c|}
\hline \multicolumn{5}{|c|}{ TABLE 1 } \\
\hline \multicolumn{5}{|c|}{ Testing the order of integration in the univariate time series } \\
\hline ARRIVALS & No regressors & An intercept & A linear time trend \\
\hline White noise & {$[0.47(0.54) 0.63]$} & {$[0.47(0.54) 0.63]$} & {$[0.47(0.54) 0.64]$} \\
\hline AR (1) & {$[0.62(0.73) 0.87]$} & {$[0.61(0.72) 0.87]$} & {$[0.61(0.72) 0.87]$} \\
\hline Bloomfield $(1)$ & {$[0.65(0.80) 1.03]$} & {$[0.64(0.80) 1.02]$} & {$[0.64(0.80) 1.02]$} \\
\hline \hline EXPORTS & No regressors & An intercept & A linear time trend \\
\hline White noise & {$[0.09(0.19) 0.33]$} & {$[0.09(0.18) 0.31]$} & {$[-0.07(0.08) 0.27]$} \\
\hline AR (1) & {$[-0.14(0.06) 0.30]$} & {$[-0.14(0.06) 0.27]$} & {$[-0.12(0.02) 0.12]$} \\
\hline Bloomfield $(1)$ & {$[-0.06(0.10) 0.33]$} & {$[-0.04(0.08) 0.27]$} & {$[-0.09(0.03) 0.13]$} \\
\hline
\end{tabular}

\begin{tabular}{|c|c|c|c|c|c|c|c|}
\hline \multicolumn{8}{|c|}{ TABLE 2} \\
\hline \multicolumn{8}{|c|}{ Estimates of the fractional differencing parameters with a single structural break } \\
\hline \multirow{2}{*}{ ARRIVALS } & \multirow{2}{*}{$\mathrm{T}_{\mathrm{b}}$} & \multicolumn{3}{|c|}{ First sub-sample } & \multicolumn{3}{|c|}{ Second sub-sample } \\
\hline & & $\mathrm{d}_{1}$ & $\alpha_{1}$ & $\beta_{1}$ & $\mathrm{~d}_{2}$ & $\alpha_{2}$ & $\mathrm{~B}_{2}$ \\
\hline White noise & 2001M1 & $\begin{array}{c}0.58 \\
{[0.48,0.69]}\end{array}$ & $\begin{array}{c}0.0150 \\
(0.168)\end{array}$ & $\begin{array}{c}0.00016 \\
(0.051)\end{array}$ & $\begin{array}{c}0.21 \\
{[0.05,0.42]}\end{array}$ & $\begin{array}{c}-0.3972 \\
(-5.319)\end{array}$ & $\begin{array}{c}0.00408 \\
(5.213)\end{array}$ \\
\hline AR (1) & 2001M1 & $\begin{array}{c}0.65 \\
{[0.60,0.81]}\end{array}$ & $\begin{array}{c}-0.0168 \\
(-0.127) \\
\end{array}$ & $\begin{array}{r}0.0042 \\
(1.198) \\
\end{array}$ & $\begin{array}{c}0.43 \\
{[0.32,0.69]}\end{array}$ & $\begin{array}{c}-0.5371 \\
(-5.279) \\
\end{array}$ & $\begin{array}{c}0.00534 \\
(4.947) \\
\end{array}$ \\
\hline \multirow{2}{*}{ EXPORTS } & \multirow{2}{*}{$\mathrm{T}_{\mathrm{b}}$} & \multicolumn{3}{|c|}{ First sub-sample } & \multicolumn{3}{|c|}{ Second sub-sample } \\
\hline & & $\mathrm{d}_{1}$ & $\alpha_{1}$ & $\beta_{1}$ & $\mathrm{~d}_{2}$ & $\alpha_{2}$ & $\mathrm{~B}_{2}$ \\
\hline White noise & 2001M3 & $\begin{array}{c}0.26 \\
{[0.03,0.42]}\end{array}$ & $\begin{array}{c}0.2720 \\
(2.132) \\
\end{array}$ & $\begin{array}{c}-0.0074 \\
(-2.189) \\
\end{array}$ & $\begin{array}{c}-0.04 \\
{[-0.20,0.09]}\end{array}$ & $\begin{array}{l}0.2017 \\
(2.066)\end{array}$ & $\begin{array}{c}-0.0021 \\
(-2.116) \\
\end{array}$ \\
\hline AR (1) & 2001M3 & $\begin{array}{c}0.31 \\
{[0.09,0.45]}\end{array}$ & $\begin{array}{c}0.2428 \\
(1.918)\end{array}$ & $\begin{array}{c}-0.0049 \\
(-1.920)\end{array}$ & $\begin{array}{c}0.02 \\
{[-0.09,0.21]}\end{array}$ & $\begin{array}{c}0.2276 \\
(2.028)\end{array}$ & $\begin{array}{c}-0.0074 \\
(-1.943)\end{array}$ \\
\hline
\end{tabular}

$\mathrm{t}$-values in parentheses. The values in brackets refer to the $95 \%$ confidence band for the fractional differencing parameters. 


\section{FIGURE 3}

$\left(d_{1}, d_{2}\right)$-values where $H_{0}$ cannot be rejected at the $5 \%$ level for white noise $u_{t}$.

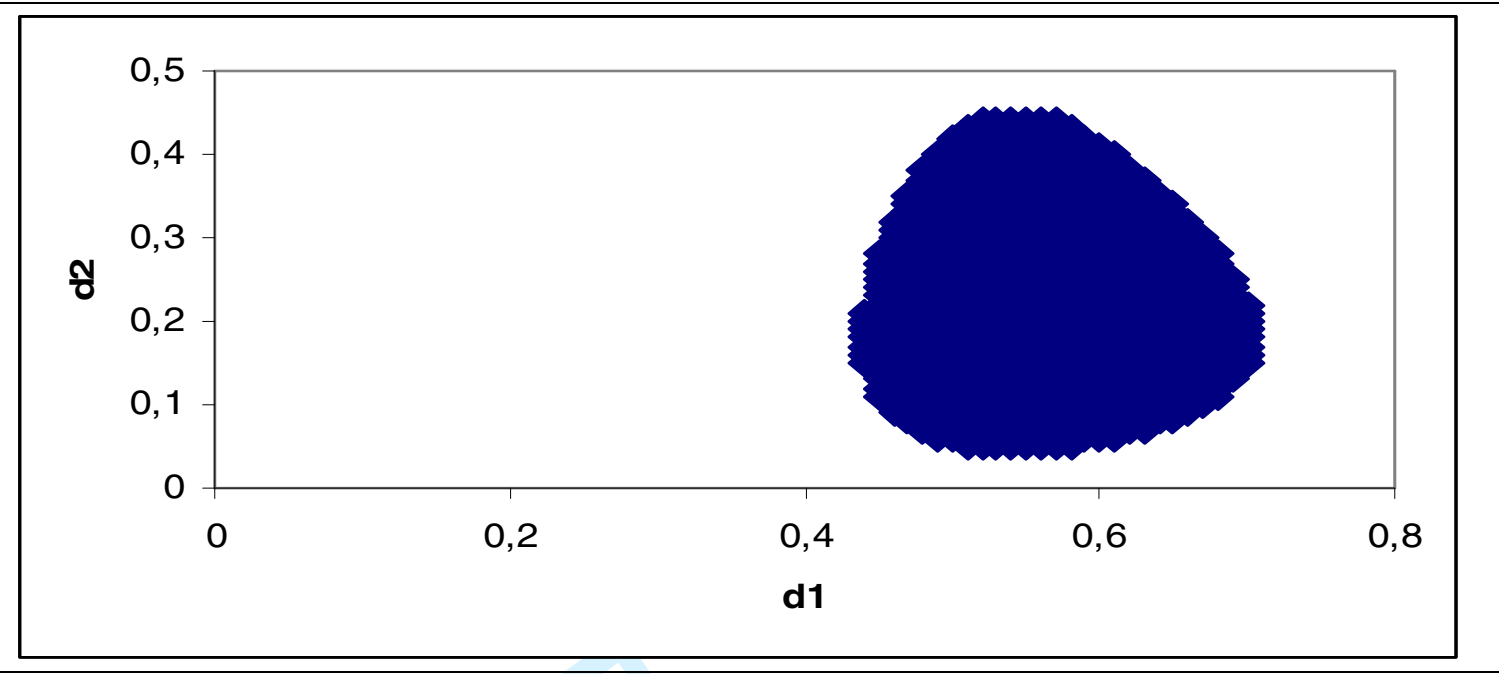

\section{FIGURE 4}

$\left(d_{1}, d_{2}\right)$-values where $H_{0}$ cannot be rejected at the $5 \%$ level for $\operatorname{VAR}(1) u_{t}$

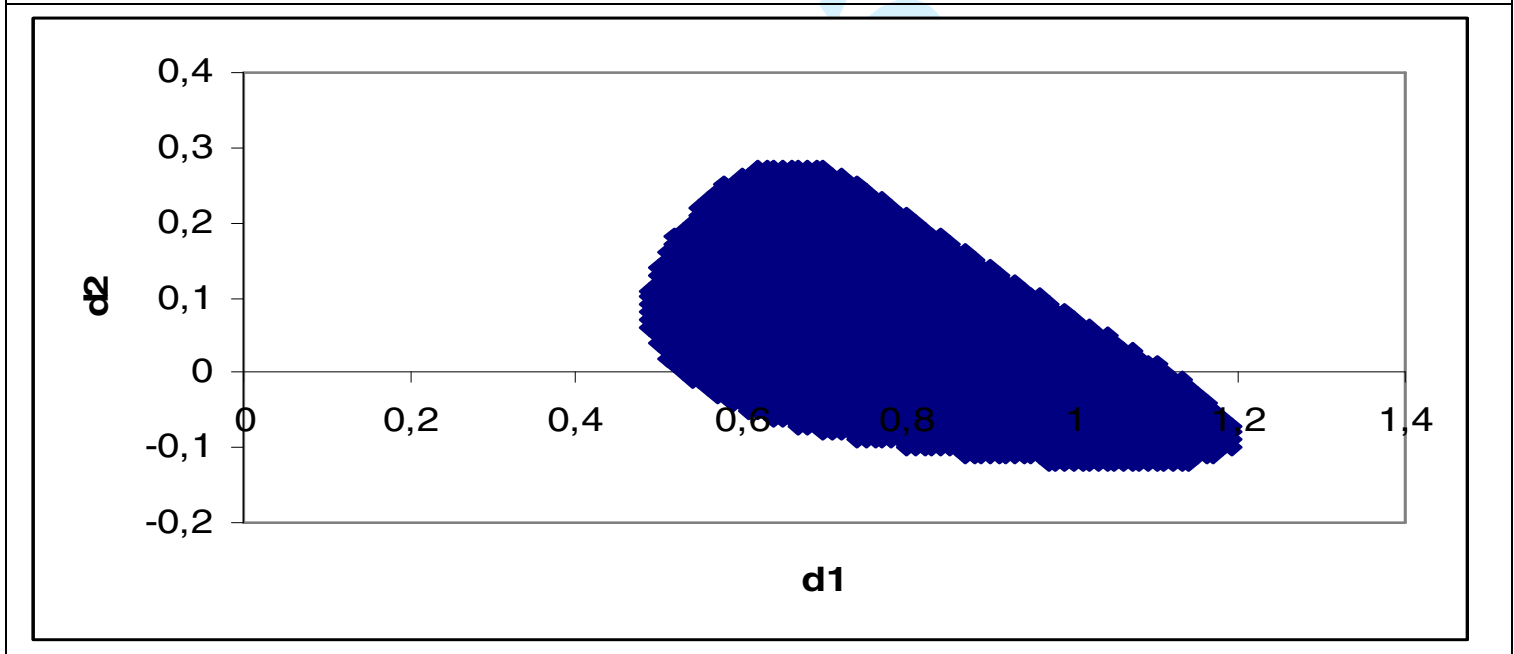


TABLE 4

Estimates of the orders of integration in a multivariate framework

\begin{tabular}{|c|c|c|}
\hline Disturbances / Order of Int. & $\mathrm{d}_{1}$ (Arrivals) & $\mathrm{d}_{2}$ (Exports) \\
\hline White noise & 0.54 & 0.18 \\
\hline VAR (1) & 0.70 & 0.04 \\
\hline
\end{tabular}

\section{TABLE 5}

Cross impulse responses of travelling on exports

\begin{tabular}{|c|c|c|}
\hline Time periods & White noise & VAR (1) \\
\hline
\end{tabular}

\begin{tabular}{|c|c|c|}
\hline 1 & -0.0248 & 0.0979 \\
\hline 2 & 0.0204 & 0.0276 \\
\hline 3 & 0.0018 & 0.0079 \\
\hline 4 & 0.0007 & 0.0033 \\
\hline
\end{tabular}

\begin{tabular}{|l|l|l|}
\hline 4 & 0.0007 & 0.0033 \\
\hline 5 & 0.0004 & 0.0018 \\
\hline 6 & 0.0002 & 0.0013 \\
\hline 7 & 0.0002 & 0.0010 \\
\hline
\end{tabular}

\begin{tabular}{|c|c|c|}
\hline 8 & 0.0002 & 0.0010 \\
\hline 9 & 0.0001 & 0.0009 \\
\hline 10 & 0.0001 & 0.0007 \\
\hline
\end{tabular}

\begin{tabular}{|l|l|l|}
\hline 10 & 0.0001 & 0.0007 \\
\hline 11 & 0.0001 & 0.0006 \\
\hline 12 & 0.0001 & 0.0005 \\
\hline 13 & 0.0000 & 0.0005 \\
\hline 14 & 0.0000 & 0.0005 \\
\hline 15 & 0.0000 & 0.0004 \\
\hline 16 & 0.0000 & 0.0004 \\
\hline 17 & 0.0000 & 0.0004 \\
\hline 18 & 0.0000 & 0.0004 \\
\hline 19 & 0.0000 & 0.0003 \\
\hline 20 & 0.0000 & 0.0003 \\
\hline
\end{tabular}




\section{FIGURE 5}

\section{Impulse response functions using the triangular identification}

i) white noise $u_{t}$

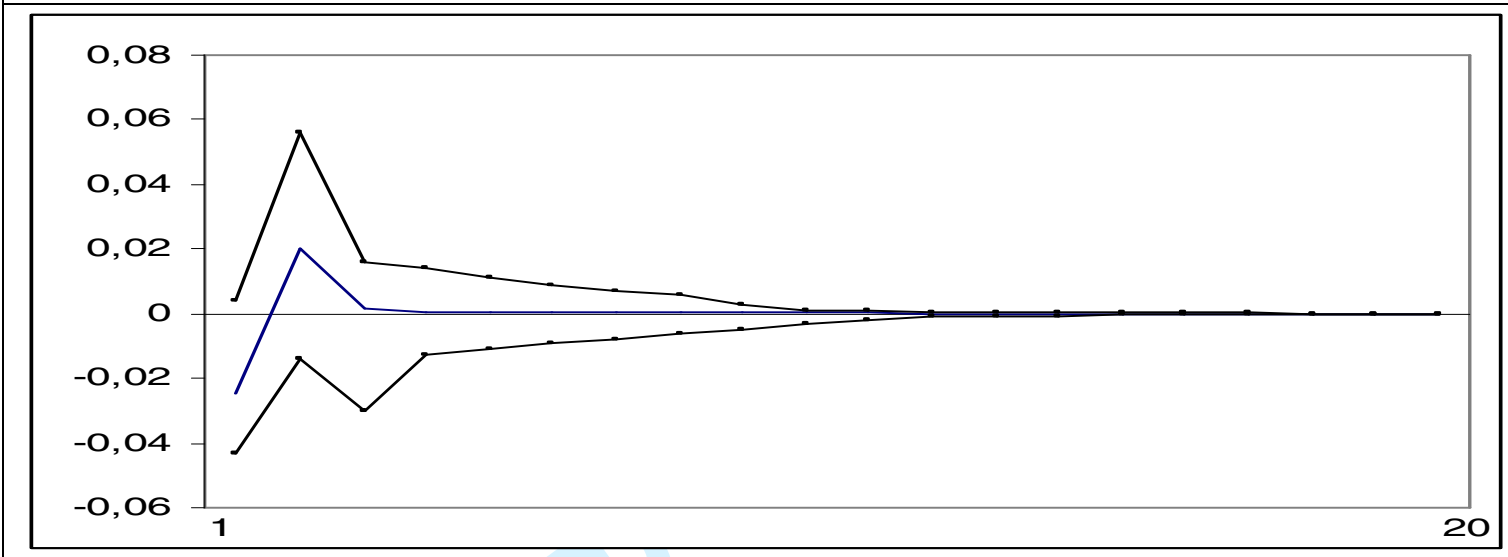

ii) $\operatorname{VAR}(1) u_{t}$

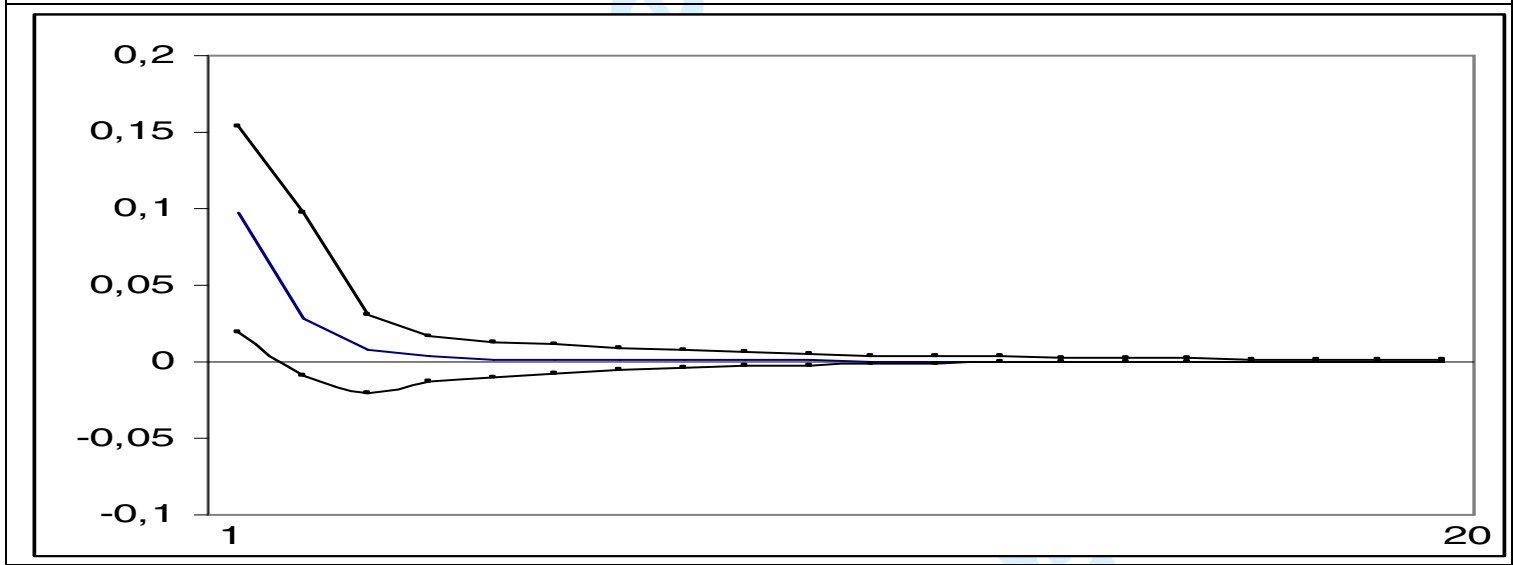

The dotted-line refers to the $95 \%$ confidence bands for the impulse responses. 


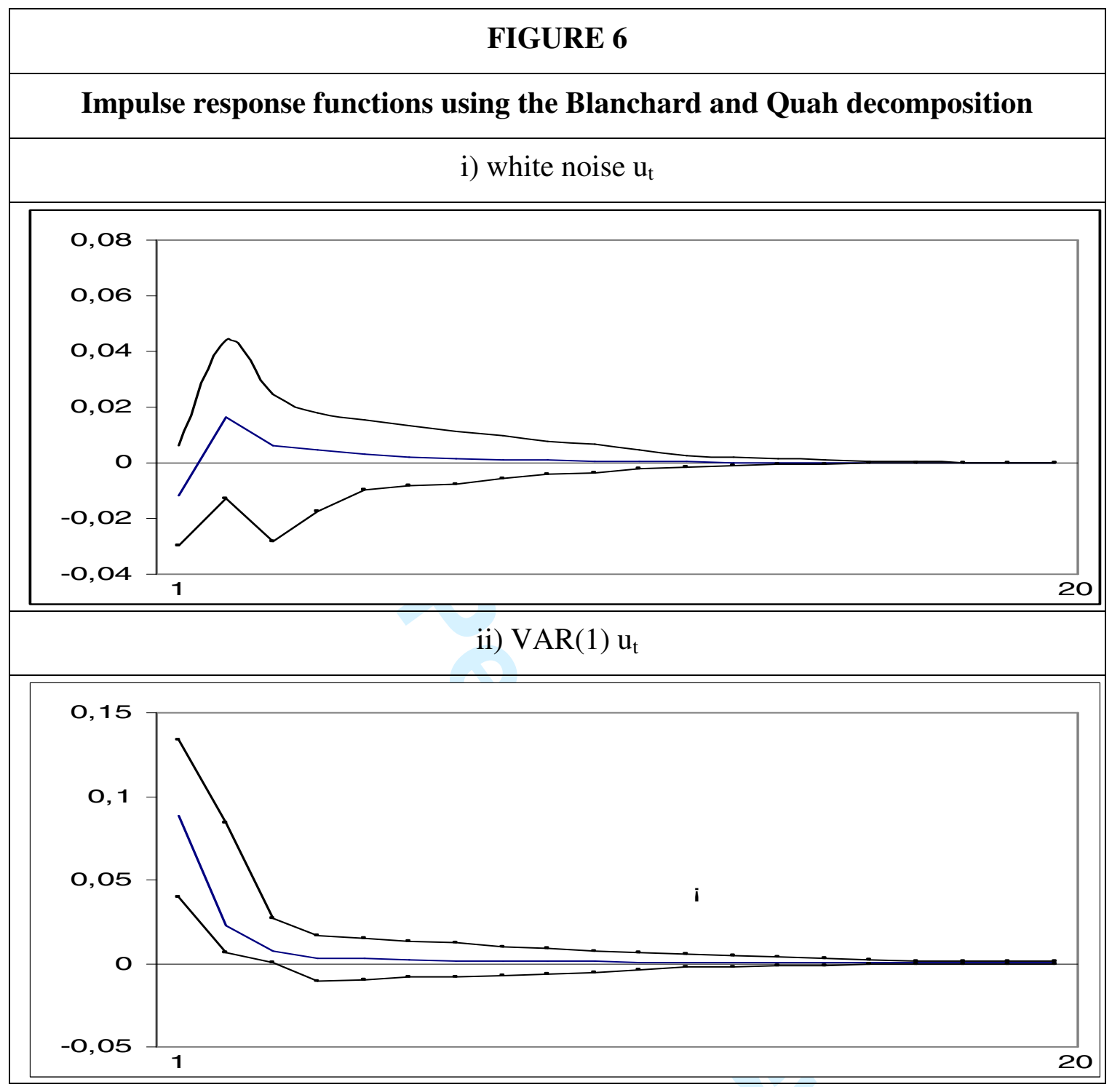

The dotted-line refers to the $95 \%$ confidence bands for the impulse responses. 